\title{
Accurate satellite-derived estimates of the tropospheric ozone impact on the global radiation budget
}

\author{
J. Joiner ${ }^{1}$, M. R. Schoeberl ${ }^{1}$, A. P. Vasilkov ${ }^{2}$, L. Oreopoulos ${ }^{1}$, S. Platnick ${ }^{1}$, N. J. Livesey ${ }^{3}$, and P. F. Levelt ${ }^{4}$ \\ ${ }^{1}$ NASA Goddard Space Flight Center, Greenbelt, MD, USA \\ ${ }^{2}$ Science Systems and Applications Inc., Lanham, MD, USA \\ ${ }^{3}$ Jet Propulsion Laboratory, Pasadena, CA, USA \\ ${ }^{4}$ Royal Netherlands Meteorological Institute (KNMI), de Bilt, The Netherlands
}

Received: 24 November 2008 - Published in Atmos. Chem. Phys. Discuss.: 2 March 2009

Revised: 24 June 2009 - Accepted: 24 June 2009 - Published: 10 July 2009

\begin{abstract}
Estimates of the radiative forcing due to anthropogenically-produced tropospheric $\mathrm{O}_{3}$ are derived primarily from models. Here, we use tropospheric ozone and cloud data from several instruments in the A-train constellation of satellites as well as information from the GEOS-5 Data Assimilation System to accurately estimate the radiative effect of tropospheric $\mathrm{O}_{3}$ for January and July 2005. Since we cannot distinguish between natural and anthropogenic sources with the satellite data, our derived radiative effect reflects the unadjusted (instantaneous) effect of the total tropospheric $\mathrm{O}_{3}$ rather than the anthropogenic component. We improve upon previous estimates of tropospheric ozone mixing ratios from a residual approach using the NASA Earth Observing System (EOS) Aura Ozone Monitoring Instrument (OMI) and Microwave Limb Sounder (MLS) by incorporating cloud pressure information from OMI. We focus specifically on the magnitude and spatial structure of the cloud effect on both the short- and long-wave radiative budget. The estimates presented here can be used to evaluate the various aspects of model-generated radiative forcing. For example, our derived cloud impact is to reduce the radiative effect of tropospheric ozone by $\sim 16 \%$. This is centered within the published range of model-produced cloud effect on unadjusted ozone radiative forcing.
\end{abstract}

\section{Introduction}

Tropospheric ozone contributes to the greenhouse effect by absorbing in the thermal infrared, primarily in the $9.6 \mu \mathrm{m}$ band. In addition, ozone absorbs sunlight in the visible Chap-

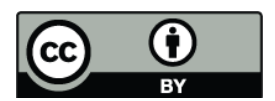

Correspondence to: J. Joiner (joanna.joiner@nasa.gov) puis band between 400 and $700 \mathrm{~nm}$ and in the ultraviolet Hartley and Huggins bands shortward of about $340 \mathrm{~nm}$. According to estimates in Forster et al. (2007), tropospheric ozone ranks as the third most important anthropogenicallyproduced gas in terms of climate impact through its direct radiative effects.

Due to the paucity of tropospheric ozone observations over the industrial era, estimates of the radiative forcing caused by changes in tropospheric ozone have been based primarily on results from chemistry transport models (CTMs) with coupled stratospheric and tropospheric chemistry and general circulation models (GCMs) with on-line chemistry (e.g., Gauss et al., 2006). In these models, the anthropogenic contribution to the tropospheric ozone burden is driven by changes in the emissions of precursors including $\mathrm{NO}_{\mathrm{x}}, \mathrm{CO}$, $\mathrm{CH}_{4}$, and other volatile organic compounds (VOCs), and variations in transport across the tropopause resulting from changes in stratospheric ozone and climate.

Clouds significantly affect the magnitude and spatial distribution of the tropospheric $\mathrm{O}_{3}$ radiative forcing, generally decreasing it by $20-60 \%$ depending on location (Forster et al., 1996). It should be noted that a large portion of the anthropogenically-produced $\mathrm{O}_{3}$ in the troposphere is present above clouds. In the long-wave, clouds on average reduce the tropospheric $\mathrm{O}_{3}$ radiative forcing, because they decrease outgoing long-wave radiation (OLR) and thus limit the amount of OLR that can be absorbed by $\mathrm{O}_{3}$. However, when clouds are located near the top of an inversion layer, they are warmer than the Earth's surface and can therefore enhance tropospheric $\mathrm{O}_{3}$ radiative forcing.

In the short-wave, clouds can increase the solar photon atmospheric pathlength if the surface albedo is less than that of the cloud. In this scenario, which occurs for a large fraction of the Earth's surface, clouds will increase the short-wave

Published by Copernicus Publications on behalf of the European Geosciences Union. 
tropospheric $\mathrm{O}_{3}$ radiative forcing. However, over bright surfaces such as sea ice, Greenland, Antarctica, and even the Sahara, the surface may have a higher albedo than the clouds above. In these areas, the cloud shielding effect may decrease the atmospheric photon pathlength and subsequently tropospheric $\mathrm{O}_{3}$ forcing.

The various satellites in the A-train afternoon constellation provide a wealth of new data that can be used to accurately compute the impact of tropospheric ozone on the local and global radiation budget. In this paper, we use several datasets from A-train satellites to compute the daily radiative effect of tropospheric $\mathrm{O}_{3}$. These satellites fly in an afternoon orbit with an ascending equator crossing time of 13:30 UT.

The radiative effect (RE) is defined here as the net change in irradiance at the tropopause produced by tropospheric ozone (anthropogenic and natural). This differs from the definition of radiative forcing used in Forster et al. (2007) in two respects. Firstly, our RE calculation is not dynamically adjusted to allow stratospheric temperatures to readjust to radiative equilibrium. Unadjusted calculations are often referred to as instantaneous, though they may be diurnally averaged. The adjustment produces a decrease of between 8 and $20 \%$ as compared with unadjusted values (e.g., Hauglustaine and Brasseur, 2001; Berntsen et al., 1997; Haywood et al., 1998).

Secondly, our calculation uses the total column tropospheric ozone, whereas the radiative forcing definition in Forster et al. (2007) refers to the anthropogenic component. It is not possible to disentangle the anthropogenic contribution to the tropospheric $\mathrm{O}_{3}$ column from that produced in nature with our satellite-derived data set. Therefore, our tropospheric $\mathrm{O}_{3}$ perturbation is the satellite-derived column-mean mixing ratio (i.e., the reference is with respect to zero tropospheric ozone). In other words, no distinction is made between anthropogenically- and naturally-produced $\mathrm{O}_{3}$. Our results thus represent an upper bound on the radiative forcing as defined in Forster et al. (2007). While our radiative effect differs from the commonly-used radiative forcing definition, it is relatively straight-forward to compute the radiative effect with present day model-generated tropospheric $\mathrm{O}_{3}$ (anthropogenic and natural) and to compare this directly with our satellite-derived results. It is also appropriate to qualitatively and quantitatively compare various aspect of the radiative effect and forcing as we have done in this work.

Tropospheric ozone is derived from a residual approach that combines information from the Ozone Monitoring Instrument (OMI) and Microwave Limb Sounder (MLS) flying on the National Aeronautics and Space Administration (NASA) Earth Observing System (EOS) Aura satellite. This approach builds upon the work of Ziemke et al. (2006) and Schoeberl et al. (2007). We use cloud and surface properties from the NASA EOS Aqua Moderate Resolution Imaging Spectroradiometer (MODIS) and OMI.

With nearly coincident datasets of cloud properties and tropospheric ozone, we compute the tropospheric $\mathrm{O}_{3}$ radia- tive effect on a daily near-global basis at relatively high spatial resolution. The use of these data sets results in improved estimates of tropospheric $\mathrm{O}_{3}$ radiative effect as compared with previous studies. We specifically isolate the impact of clouds separately on the long- and short-wave. We also examine spatial and temporal variations in the sensitivity of the radiative effect to a given change in tropospheric $\mathrm{O}_{3}$ mixing ratio.

The organization of the paper is as follows: Sect. 2 and the appendices describe the radiative transfer calculations and input data sets in detail. Results of radiative calculations are presented in Sect. 3. Section 4 discusses our results in the context of model-generated anthropogenic radiative forcing estimates that provide the basis for magnitudes and uncertainties reported by the Intergovernmental Panel for Climate Change (IPCC). Conclusions are given in Sect. 5.

\section{Algorithms and datasets used in radiative transfer calculations}

\subsection{Radiative transfer calculation}

The radiative transfer calculations are performed using standalone versions of algorithms developed by Chou and Suarez $(1994,2002,2003)$ (henceforth referred to as CS). These algorithms are part of the Goddard Earth Observing System 5 Data Assimilation System (GEOS-5 DAS) (Rienecker et al., 2007) and have been used in previous versions of the GEOSDAS and other models in the Goddard Laboratory for Atmospheres. Separate algorithms were developed for long-wave (LW) and short-wave (SW) components. Appendix A gives a detailed description of the algorithm.

\subsection{Tropospheric ozone mixing ratio from OMI/MLS}

The tropospheric column-mean mixing ratio is estimated using a residual method with retrievals of total and stratospheric column ozone from OMI and MLS, respectively, using a slightly modified version of the algorithm developed by Schoeberl et al. (2007). OMI is a nadir-viewing radiometer that measures the solar irradiance and Earth backscattered radiance from $270-500 \mathrm{~nm}$ with a spectral resolution of approximately $0.5 \mathrm{~nm}$ (Levelt et al., 2006). It provides nearglobal coverage with a nadir pixel size of $13 \times 24 \mathrm{~km}$ in the UV-2 channel used to retrieve total column ozone.

The OMI total column ozone is from collection 3 and is derived with an algorithm similar to the Total Ozone Mapping Spectrometer (TOMS) version 8 (known as OMTO3 version 8.5) (Bhartia and Wellemeyer, 2002). This is one of two OMI total column $\mathrm{O}_{3}$ products; the other is based on the Differential Optical Absorption Spectroscopy (DOAS) approach. McPeters et al. (2008) and Kroon et al. (2008a,b) discuss the validation of the collection 2 OMI total ozone data sets. There has been no significant drift in the OMI total columns as compared with the ground-based network 
of Dobson and Brewer instruments (McPeters et al., 2008). The systematic difference between OMTO3 and groundbased data increased slightly from collection $2(0.26 \%)$ to $3(-1.3 \%)$ (G. Labow, personal communication, 2008).

One major change in OMTO3 subsequent to these publications is the incorporation of optical centroid cloud pressures (OCCPs) from the OMI rotational-Raman cloud product (OMCLDRR) of Joiner and Vasilkov (2006). The OMI cloud pressures replace a climatology of cloud-top pressures derived from thermal infrared measurements. This change eliminated significant errors in the total column ozone in the presence of bright clouds identified by Joiner et al. (2006) and lessened cloud-induced noise in the retrieved total column ozone similar to the results of Vasilkov et al. (2004). It also reduced differences between the OMI DOAS and OMI TOMS total columns that were noted by Kroon et al. (2008b).

MLS makes millimeter and submillimeter observations by scanning through the atmospheric limb. We use stratospheric column ozone from MLS version 2.2 that has been validated by Froidevaux et al. (2008), Livesey et al. (2008), and Petropavlovskikh et al. (2008). The stratospheric columns from version 2.2 are in better agreement with correlative data sets than version 1.5 (e.g., Petropavlovskikh et al., 2008) with MLS slightly higher than SAGE II $(\sim 1 \%)$ in the lower stratosphere (Froidevaux et al., 2008).

Because MLS makes measurements along the Aura orbital track within a narrow swath, its retrievals must be interpolated between orbits to provide daily global estimates of the stratospheric column ozone. Here, MLS ozone profile data between 10 and $215 \mathrm{hPa}$ are spread with a trajectory model as in Schoeberl et al. (2007). The stratospheric column ozone derived from this method is then subtracted from the retrieved OMI total column ozone to yield estimates of the tropospheric column ozone.

Schoeberl et al. (2007) compared a previous version of the OMI/MLS column ozone between $200 \mathrm{hPa}$ and the surface with ozone sonde data. In the tropics, the mean difference was 2.4 Dobson Units (DU) (sonde higher) with a standard deviation of approximately $5 \mathrm{DU}$. The differences were larger at middle latitudes with OMI/MLS consistently lower than the ozonesondes by 1-7 DU depending on the season. Standard deviations at mid-latitudes were also higher with values between about 9 and 13 DU also dependent on season.

We have improved the residual approach of Schoeberl et al. (2007) by reducing the influence of a priori information in cloudy conditions. In cloudy situations, a portion of the $\mathrm{O}_{3}$ column beneath the clouds is hidden from the satellite. An estimate of this hidden amount (i.e., the a priori information, also commonly referred to as the ghost column) based on climatology is added to the measured column to provide an estimate of the total column. To compute the columnmean volume mixing ratio, $\bar{\chi}$, we use the column measured by OMI, $\Omega_{\text {meas }}$, rather than the estimated total column ozone that includes an assumed amount of ozone in the hidden col- umn. Note that the sensitivity of OMI observations to tropospheric $\mathrm{O}_{3}$ varies with pressure due to both cloud shielding and Rayleigh scattering.

The $\mathrm{O}_{3}$ column, $\Omega$, in DU between any two pressure levels is given by

$\Omega=0.789 \int_{P_{\mathrm{top}}}^{P_{\mathrm{botom}}} \chi d P$,

(Dessler, 2005, e.g.,), where $\chi$ is the $\mathrm{O}_{3}$ volume mixing ratio in units ppmv, and $P_{\text {top }}$ and $P_{\text {bottom }}$ are the top and bottom pressure levels in hPa. In this work, we define $\bar{\chi}$ as the column-mean mixing ratio corresponding to a broad homogeneous tropospheric layer that produces the observed tropospheric column. We next develop the concept of an effective layer represented by $\bar{\chi}$. The top of this layer is the tropopause, and we define the lower pressure boundary to be $P_{\text {eff. }}$ Then, Eq. (1) can be rewritten as

$\bar{\chi}=1 / 0.789\left(\Omega_{\text {meas }}-\Omega_{\text {strat }}\right) /\left(P_{\text {eff }}-P_{\text {trop }}\right)$,

where $P_{\text {trop }}$ is the tropopause pressure (in $\mathrm{hPa}$ ) and $\Omega_{\text {strat }}$ is the stratospheric column ozone.

A first order estimate of $P_{\text {eff }}$ can be obtained using the concepts of radiative cloud fraction $(f)$ and optical centroid cloud pressure (OCCP or $\left.P_{\text {cld }}\right) . f$ is defined as the fraction of total pixel radiance contributed by the cloudy portion of the pixel. $P_{\text {cld }}$ is the pressure of a Lambertian surface with equivalent reflectivity of $80 \%$ that produces the observed amount of rotational-Raman scattering for a given $f$. The accuracy of this mixed Lambertian model has been examined in detail by Vasilkov et al. (2008).

The measured portion of the tropospheric column, $\Omega_{\text {trop }}$, is defined as $\Omega_{\text {meas }}-\Omega_{\text {strat }}$. Then, $\Omega_{\text {trop }}$ can be written as

$\Omega_{\text {trop }}=0.789\left[(1-f) \chi_{\text {clr }}\left(P_{\text {surf }}-P_{\text {trop }}\right)+f \chi_{\text {cld }}\left(P_{\text {cld }}-P_{\text {trop }}\right)\right]$,

where $\chi_{\mathrm{clr}}$ and $\chi_{\mathrm{cld}}$ are the column-mean mixing ratios for layers between the tropopause and either the surface or $P_{\text {cld }}$, respectively. Setting $\chi_{\text {clr }}=\chi_{\text {cld }}=\bar{\chi}$, Eq. (3) can be rewritten as

$\Omega_{\text {trop }}=0.789\left[\bar{\chi}\left(P_{\text {eff }}-P_{\text {trop }}\right)\right]$,

where

$P_{\text {eff }}=(1-f) P_{\text {surf }}+f P_{\text {cld }}$.

Note that for bright pixels $(f=1), \bar{\chi}$ can be computed accurately and represents the column-mean mixing ratio between the tropopause and the optical centroid cloud pressure, $P_{\text {cld }}$. This is precisely the quantity that is needed for accurate radiative transfer calculations in the short-wave.

The computation of $\bar{\chi}$ with this approach reduces noticeable cloud-induced artifacts in the column-mean mixing ratio. As a result, pixels with high cloud amounts are no longer discarded. The agreement between satellite-derived and sonde-based tropospheric column ozone is significantly 

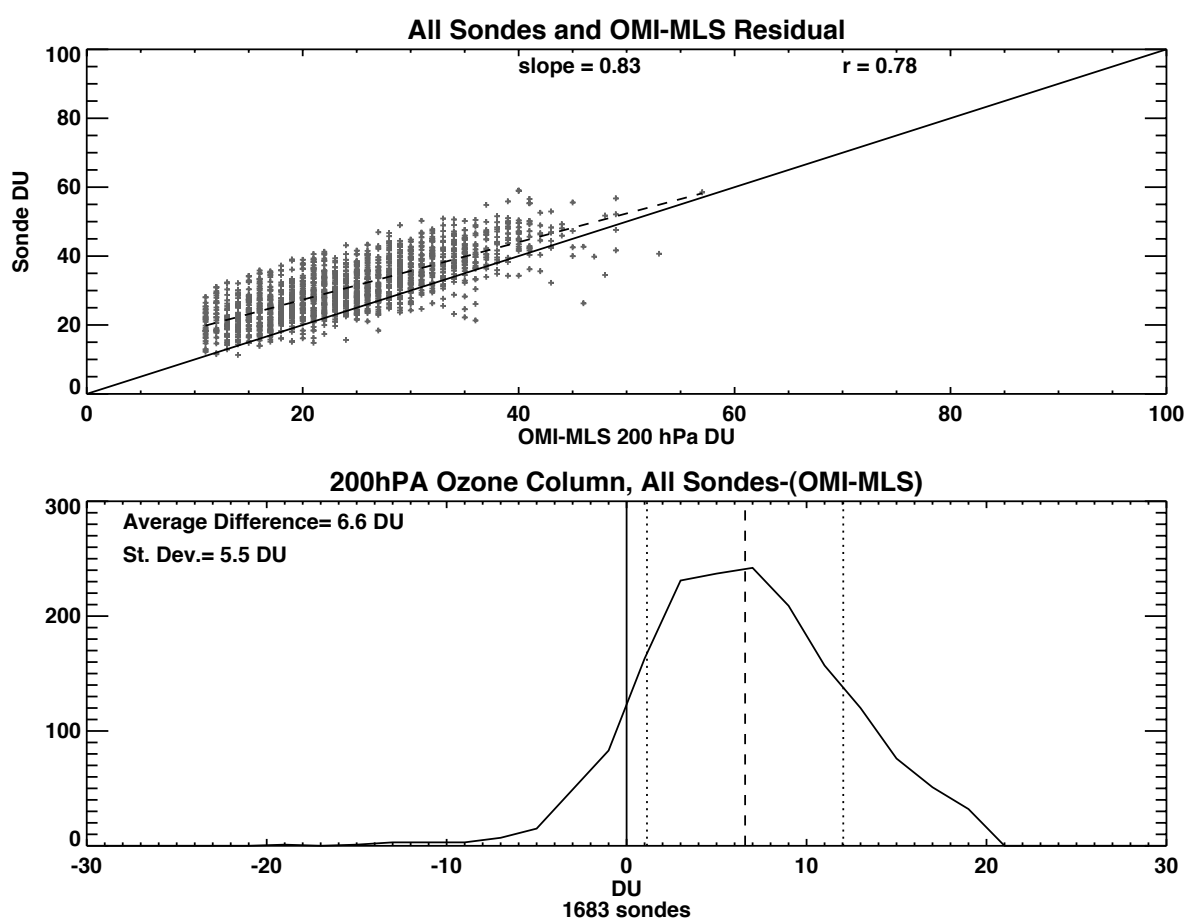

Fig. 1. Top panel: Scatter diagram of column $\mathrm{O}_{3}$ between $200 \mathrm{hPa}$ and the surface as derived from OMI and MLS (horizontal-axis) and ozonesonde database (vertical-axis) of 1683 sondes. Bottom panel: Histogram of the ozonesonde and OMI/MLS $200 \mathrm{hPa}$ to surface column ozone difference.

improved as compared with Schoeberl et al. (2007) (see Fig. 1). This analysis is similar to that conducted in Schoeberl et al. (2007) in that the same ozonesonde database covering late 2004-2006 is used and we also focus on the $200 \mathrm{hPa}$ to-surface column (200TSC) amount of ozone in order to remove issues associated with the definition of the tropopause. In Fig. 1, all sondes are included rather than separated by latitude or season as in Schoeberl et al. (2007). The sample is slightly smaller here due to the use of a different flagging scheme. The overall correlation coefficient between sonde and satellite 200TSC in this work is 0.78. In Schoeberl et al. (2007), the correlations were $0.45-0.68$ in the northern hemisphere extra tropics and 0.73 in the tropics. The bias between satellite and sonde increased slightly here with an average value of 6.6 DU as compared with the range of 0.85 7.5 shown in Schoeberl et al. (2007). In the tropics, the bias, standard deviation, and correlation here are 5.0 DU, 4.5 DU, and 0.86 , respectively as compared with the Schoeberl et al. (2007) results 2.4 DU, 5.4 DU, and 0.73.

The specification of the tropopause affects our radiative calculation in two ways. Firstly, the selection of a particular tropopause definition determines the amount of ozone assigned to the troposphere and thus the derived column-mean mixing ratio from the residual method. Secondly, it determines how much of the atmosphere is included in the calculation. This particularly affects the computed long-wave radiative effect owing to the high sensitivity to ozone near the tropopause.
In this work, we apply two definitions of the tropopause height. The first is the standard lapse rate definition (the lowest level at which the lapse rate decreases to $2 \mathrm{~K} / \mathrm{km}$ or less provided that the average lapse rate between this level and all higher levels within $2 \mathrm{~km}$ does not exceed $2 \mathrm{~K} / \mathrm{km}$ ). The second method relies primarily on a dynamic definition and uses the lowest altitude corresponding to 3.5 PVU (Potential Vorticity Units), the $380 \mathrm{~K}$ surface, the cold point, or the lapse rate definition. The PV tropopause definition is usually lowest in altitude outside the tropics. We have chosen to present results (of derived mixing ratios and computed radiative effect) obtained using the lapse-rate definition, because this is the definition most commonly used in other studies referred to here. The sensitivity of our results to the specification of the tropopause is further examined in Appendix B4.

Figure 2 shows examples of the derived daily columnmean mixing ratio, $\bar{\chi}$, from OMI/MLS. Figure 3 similarly shows monthly mean fields of $\bar{\chi}$. Tropospheric $\mathrm{O}_{3}$ has significant spatial variations on both daily and seasonal time scales. In the remote tropical Pacific, areas of deep convection (high values of cloud fraction and optical thickness) correspond to low $\mathrm{O}_{3}$ mixing ratios shown in Fig. 2. The reported mixing ratios in the presence of bright clouds represent those inside the upper portions of the clouds (Ziemke et al., 2009). The low mixing ratios can result from $\mathrm{O}_{3}$-poor boundary layer air that is lifted into the upper troposphere (Kley et al., 1996; Folkins et al., 2002; Solomon et al., 2005). 

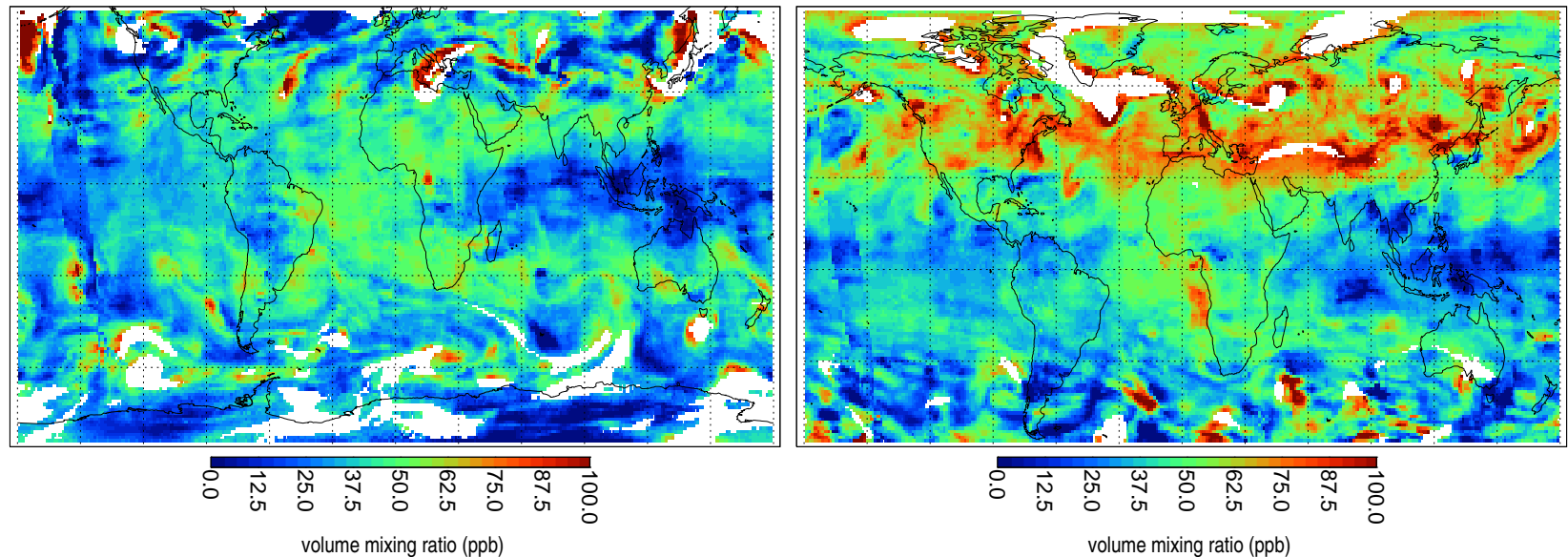

Fig. 2. Column-mean $\mathrm{O}_{3}$ tropospheric mixing ratio (between tropopause and the effective lower pressure boundary $P_{\text {eff }}$ as described in the text) derived from OMI/MLS for 1 January (left) and 1 July 2005 (right). Missing values (white areas) occur where either no data are available or where quality control checks flag the data as suspect (see text).
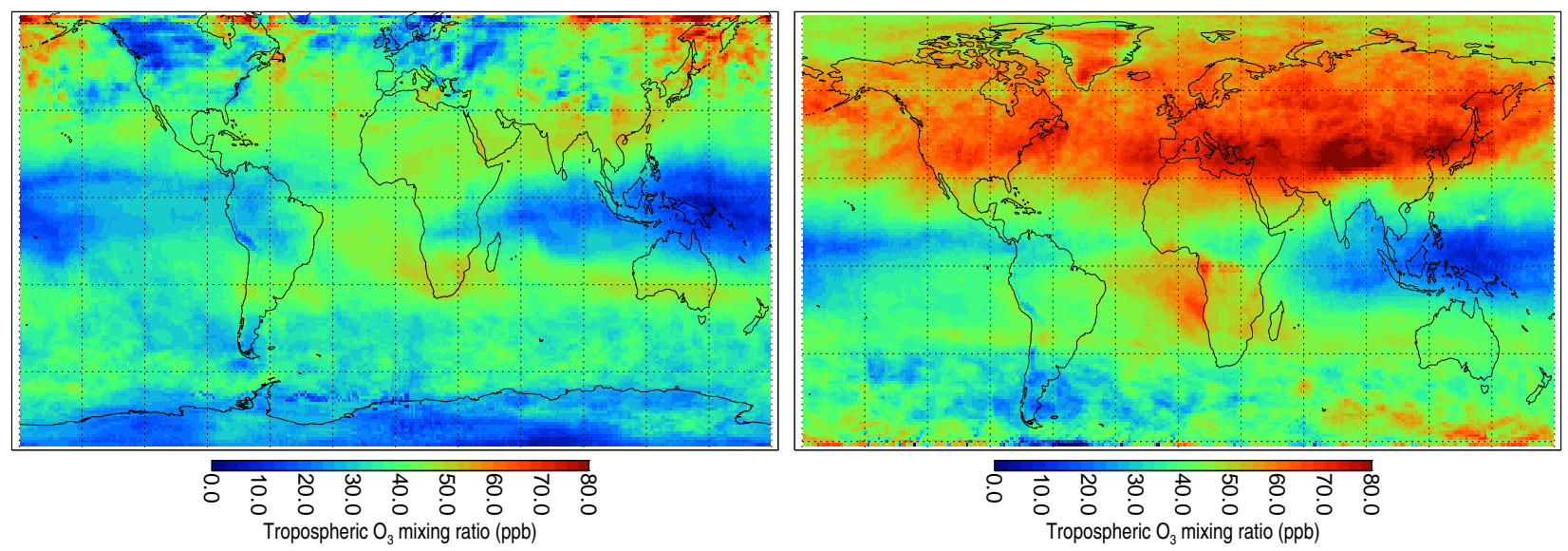

Fig. 3. Monthly average column-mean tropospheric $\mathrm{O}_{3}$ mixing ratio (between the tropopause and approximately the mean effective lower pressure boundary $P_{\text {eff }}$ ) for January (left) and July (right) 2005 .

Similar to Schoeberl et al. (2007), we filter out suspect data. Data are not used when the tropopause is at a pressure greater than $320 \mathrm{hPa}$, primarily to minimize excessive extrapolation of MLS data (only used down to $215 \mathrm{hPa}$ ). Data are also discarded when the derived tropospheric column amount is greater than $120 \mathrm{DU}$. This can occur when the tropopause pressure is ill-defined or may indicate situations where the trajectory approach is suspect. When the derived value of $\bar{\chi}$ is less than zero, it is set equal to zero. OMI cloud pressures are currently not used to derive column ozone over snow and ice. Although the total measured column is accurately determined over these bright surfaces, the column mean mixing ratio may be underestimated in the presence of an optically thick cloud over snow or ice because $P_{\text {eff }}$ is overestimated. Note also that there are no OMI data in the polar night.
At middle and high latitudes, some high values of the column-mean mixing ratio appear in the daily and monthly fields. These high values are likely due in part to $\mathrm{O}_{3}$ of stratospheric origin that is transported into the troposphere during fold events. Some of these data are flagged either to avoid excessive extrapolation of MLS data or because the tropopause is ill-defined, leading to suspect values of the $\mathrm{O}_{3}$ mixing ratio. However, some of the high values are retained in our data set. Therefore, present-day model simulations of tropospheric $\mathrm{O}_{3}$ (and its associated radiative effect) from all sources, including stratosphere-troposphere exchange, can be evaluated with the satellite estimates. In such a comparison, model data should be similarly flagged. 

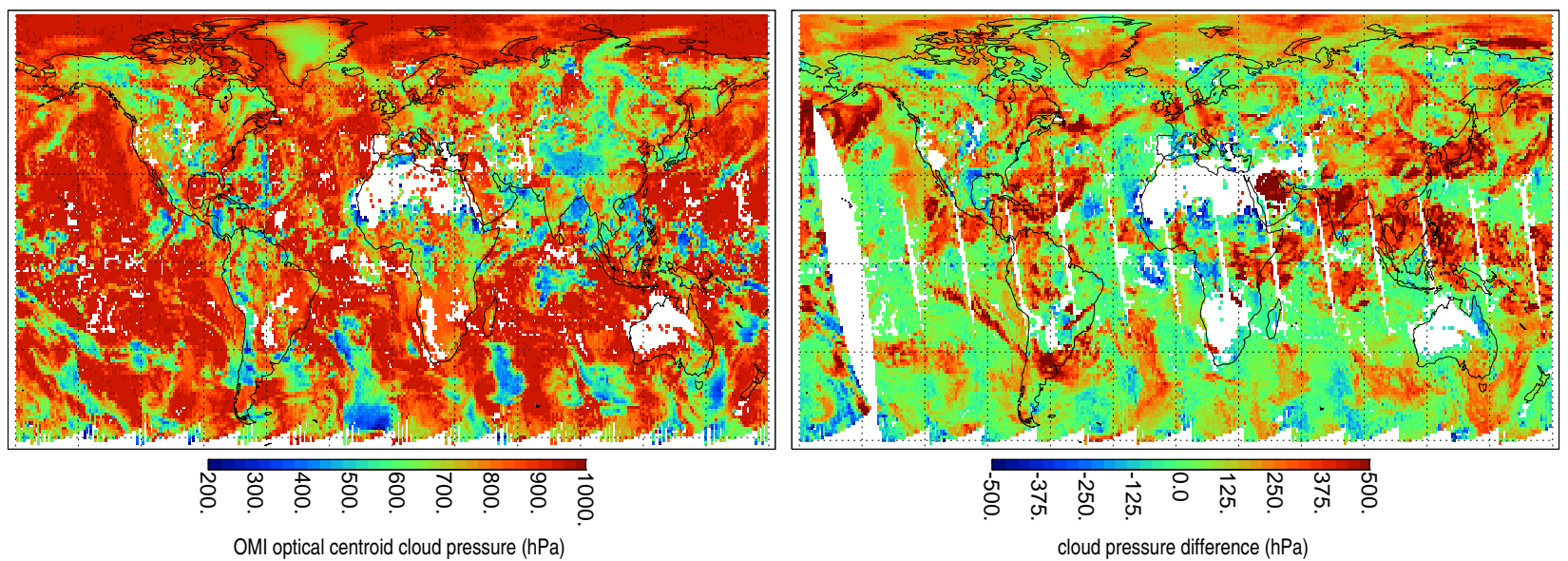

Fig. 4. Gridbox mean optical centroid cloud pressure (OCCP) from OMI (left) and OCCP minus MODIS cloud-top pressure (right) for 1 July 2005.

\subsection{Cloud parameters from MODIS}

We use estimates of cloud optical thickness, effective radius, and phase from MODIS daily gridded $1^{\circ} \times 1^{\circ}$ level 3 (L3) data sets (Platnick et al., 2003). The dataset includes gridpoint means and histograms of cloud optical depth separately for ice and water clouds. We also use the associated cloud fractions for ice and water clouds. These are the fractions of successful cloudy retrievals with respect to all successful retrievals within a gridbox. Note that MODIS cloud optical thicknesses have an upper limit of $\sim 100$. This has a minimal impact on our short-wave calculations, because cloud reflectance and transmittance are effectively saturated at this value. Lastly, we use mean daytime cloud-top pressures. These are derived from either the $\mathrm{CO}_{2}$ slicing approach of Menzel et al. (1992) or from the infrared $11 \mu \mathrm{m}$ window channel brightness temperature as described in Platnick et al. (2003).

\subsection{Optical centroid cloud pressure (OCCP) from OMI}

Significant differences exist between cloud-top pressures derived from thermal infrared measurements and optical centroid cloud pressures (OCCP) derived from photon-path-type measurements. OCCP can be derived from a variety of techniques including oxygen A-band absorption (e.g., Rozanov et al., 2004), oxygen dimer absorption (e.g., Sneep et al., 2008), and rotational-Raman scattering (e.g., Joiner et al., 2004). The latter two have been implemented with OMI and the first is used in the A-train with the POLDER instrument. Sneep et al. (2008) showed with radiative transfer calculations that OCCPs derived from these three approaches should be very similar. In fact, the retrieved pressures are quite similar (Sneep et al., 2008; Vasilkov et al., 2008) with remaining differences believed to be due mainly to algorithm and instrumental effects. Therefore, we believe that the wavelength dependence of the light path can be reasonably represented by any of these OCCPs for wavelengths spanning the near IR through the UV. Vasilkov et al. (2008) showed that the derived OCCPs were consistent with simulations that used optical depth profiles derived from a combination of CloudSat radar reflectivity profiles (Stephens et al., 2008) and MODIS cloud optical depths.

Ziemke et al. (2009) have shown that the large differences between MODIS cloud-top pressures and OMI OCCPs in convective clouds are due in part to the fact that clouds are vertically inhomogeneous. CloudSat/MODIS retrievals show that tropical deep convective clouds are relatively thin near the top with cloud extinctions peaking between $\sim 400$ and $600 \mathrm{hPa}$. By computing ozone Jacobians within convective clouds, Ziemke et al. (2009) demonstrate that photons penetrate significantly inside these clouds, reaching pressures near the OCCP with enhanced absorption due to multiple scattering in the upper portions of the clouds. They further demonstrated that the concept of the OCCP can be used to estimate $\mathrm{O}_{3}$ absorption inside clouds with good accuracy. Therefore, the OCCP is more appropriate than the cloud-top pressure for short-wave radiative calculations.

Here we use OCCPs from the OMI rotational-Raman algorithm (Joiner and Vasilkov, 2006). Figure 4 shows a sample day of retrieved OCCP. Over ocean the OCCPs are general large (low altitude clouds), except in regions of tropical deep convection and frontal convection in the extra-tropics. The difference between the OMI OCCP and the MODIS cloudtop pressure is also shown in Fig. 4. The largest differences are found in conjunction with deep or frontal convection, especially around the edges of the convection where outflow produces thin cirrus above lower level water clouds. Vasilkov et al. (2008) showed that in such situations when the upper cirrus deck has an optical thickness of $\sim 10$ or less, the OCCP should be close to the top of the lower cloud deck. 
The OCCP is almost always greater than the cloud top pressure. However, the optical centroid pressure may be less than the cloud top pressure due to changes in clouds that occur between the Aqua and Aura overpasses (at this time, the difference was $\sim 15 \mathrm{~min}$ ). Errors in either the MODIS or OMI cloud pressures may also produce this type of difference. UV-absorbing aerosol (e.g., dust or smoke) above or embedded within clouds can erroneously reduce the retrieved OMI cloud fractions and pressures (Vasilkov et al., 2008). MODIS cloud pressures derived from the window brightness temperature technique are also prone to errors when there are temperature inversions or when cloud emissivity is less than unity.

Details regarding the use of the MODIS and OMI retrieved cloud parameters are given in Appendices B1-B2 along with sensitivity studies.

\subsection{Meteorological parameters from the GEOS-5 data assimilation system}

Atmospheric profiles of temperature, water vapor, and stratospheric ozone as well as surface skin temperature are taken from the Goddard Earth Observing System 5 Data Assimilation System (GEOS-5 DAS) (Rienecker et al., 2007). The GEOS-5 DAS is run at a horizontal resolution of $0.5^{\circ} \times 0.625^{\circ}$. The analysis system uses the Gridpoint Statistical Interpolation (GSI) scheme developed at the National Oceanic and Atmospheric Administration (NOAA) National Centers for Environmental Prediction (NCEP) that is part of their operational global weather prediction system.

The system ingests satellite data from operational meteorological satellites including microwave and infrared radiance data from the TIROS Operational Vertical Sounder (TOVS), and the NASA Aqua Atmospheric InfraRed Sounder (AIRS) and Advanced Microwave Sounding Unit A (AMSU-A). These data provide information about the global temperature and humidity fields. Stratospheric $\mathrm{O}_{3}$ distributions are constrained by the assimilation of Satellite Backscatter UltraViolet 2 (SBUV-2) spectrometer retrievals. Stratospheric $\mathrm{O}_{3}$ impacts our calculations of the tropospheric $\mathrm{O}_{3}$ radiative effect in that it affects the downwelling flux at the tropopause.

Short-wave results do not depend significantly on the temperature and water vapor profiles. Long-wave calculations depend on all of the GEOS-5 parameters used here. GEOS5 temperatures and humidity have been compared with reanalyses from both the European Center for Medium-range Weather Forecasting (ECMWF) and the US National Centers for Environmental Prediction (NCEP). The zonal mean temperature differences in the troposphere are typically small $(<\sim 1.5 \mathrm{~K})$. The dependence of the $\mathrm{O}_{3} \mathrm{RE}$ on water vapor is relatively small except in the tropics where GEOS-5 has a negative(positive) bias in the lower(upper) troposphere versus both ECMWF and NCEP (zonal mean differences of the order of $20 \%$ or less).
The largest uncertainty of the $\mathrm{O}_{3} \mathrm{RE}$ calculation with respect to the analysis data set is likely to be related to the surface skin temperature over land. A significant effort has been expended at the GMAO to provide reasonable estimates of the surface skin temperature. However, there are biases remaining in the GEOS-5 skin temperature as there are for all analysis systems (M. Bosilovich, private communication, 2009). We calculated the day-night global difference in the tropospheric ozone radiative effect that is due primarily to surface skin temperature over land $\left(0.12 \mathrm{~W} / \mathrm{m}^{2}\right)$. As the skin temperature errors are expected to be much smaller than the day-night difference, this may be considered as an upper bound on the radiative effect error due to uncertainties in the surface skin temperature.

\subsection{Surface albedos and emissivity}

In the short-wave, the CS code accepts spectrally constant albedos for direct and diffuse fluxes in the UV/Visible region. We interpolate the albedos to $600 \mathrm{~nm}$, the approximate peak of the Chappuis $\mathrm{O}_{3}$ band.

Over land, we use 16-day gridded albedos from the MODIS filled-land surface albedo product (MOD43B3) (Lucht et al., 2000) and assume a Lambertian surface. Separate values are provided for white and black skies. The former (latter) are used for calculations in cloudy (clear) skies.

Over ocean, we use a model of the surface albedo from Jin et al. (2004). The albedo varies with surface wind speed. Therefore, we use estimates of the $2 \mathrm{~m}$ wind speed from the GEOS-5 DAS.

We use the Near Real-Time SSM/I EASE-Grid Daily Global Ice Concentration and Snow Extent (NISE) data set (Nolin et al., 1998) to identify gridboxes containing sea ice. If sea ice is identified and the MODIS albedo product does not provide an appropriate value, we use the $380 \mathrm{~nm}$ reflectivity from a TOMS monthly climatology (C. Ahn, personal communication, 2008).

Note that the OMI-TOMS algorithm uses a different treatment for surface albedo. In order to calculate an effective cloud fraction in the case of partial cloud cover, the current algorithm assumes that the surface and cloud reflectivities are 15 and $80 \%$, respectively. The former value was chosen such that the effect of aerosol is incorporated into the surface albedo. This approach will produce small errors in the retrieved $\mathrm{O}_{3}$ column in the presence of clouds when the surface albedo deviates from the assumed value. There are plans to use a wavelength-dependent surface albedo climatology derived from OMI in future versions of the (OMI)TOMS processing to reduce this error.

In the thermal infrared, we use an annual average surface emissivity database at $1^{\circ} \times 1^{\circ}$ resolution compiled from Wilber et al. (1999). Here, we interpolate the spectral surface emissivity to a wavelength of $9.6 \mu \mathrm{m}$ where $\mathrm{O}_{3}$ absorption is at a maximum. 


\section{Results}

To derive $\bar{\chi}$, we have assumed that the mixing ratio is constant throughout the tropospheric column. Kiehl et al. (1999) used a constant mixing ratio perturbation in their radiative forcing calculations and found it to be a reasonable approximation of differences between ozonesonde data obtained in polluted and clean conditions. Kiehl et al. (1999) further examined the sensitivity of radiative forcing to this choice and found that it changed by $\pm 15 \%$ when they instead used perturbations with a constant slope in mixing ratio as a function of altitude.

For short-wave calculations, we compute the diurnallyaveraged radiative effect (RE). Because it is important to use the column-mean tropospheric mixing ratio coincident with the cloud property retrievals to compute the RE, particularly in convective regions, we assume that the MODIS Aqua daytime cloud properties and the column-mean $\mathrm{O}_{3}$ mixing ratios persist throughout day. This will create local biases where for example the mean cloud fraction at the Aqua overpass does not represent mean daily cloud fraction. We can get some estimate of the diurnal cloud effect by examining the difference in cloud fraction between the Aqua and Terra satellite that has a local overpass time approximately $3 \mathrm{~h}$ earlier. The daytime cloud fractions over ocean are slightly higher on average (by $\sim 2-3 \%$ ) over ocean and lower over land ( $\sim 3-4 \%$ ). Averaging globally gives nearly identical cloud fractions. Comparing daytime and nighttime cloud fractions is somewhat more problematic in that the algorithms are slightly different due to lack of shortwave observations at night. Comparing July 2005 Aqua daytime and nighttime cloud fractions, we find some areas with significant differences, such as over Brazil and northern Australia where cloud fractions are primarily higher at night and over eastern Mexico where cloud fractions are higher during the day. When performing a quantitative comparison of RE with present-day models, the model could be sampled during the Aqua daytime overpass to minimize the effects of the diurnal cloud variability.

We perform SW calculations every two hours at the appropriate solar zenith angle. We compared our two hour averages with one hour averages and found negligible differences in the global daily average.

For LW calculations, we leave the cloud properties and tropospheric $\mathrm{O}_{3}$ fixed at the Aqua MODIS 13:30 UT values as we did for the SW. We average the RE computed using GEOS-DAS data at the synoptic time closest to the A-train 01:30 UT and 13:30 UT overpasses. In this way, we capture to a large degree the high and low extremes of the surface skin temperature. This averaging may produce local biases in the computed RE over areas such as subtropical deserts where the diurnal skin temperature variation is large and potentially asymmetric. Over ocean, the diurnal variation in sea surface temperature is insignificant. We calculated the global 01:30-13:30 difference in the RE for January 2005 $\left(0.12 \mathrm{~W} / \mathrm{m}^{2}\right)$. This is an upper limit for the error in RE that would result from assuming a constant skin temperature equal to either the $01: 30$ or 13:30 value. The actual error produced by averaging the 01:30 and 13:30 RE will be much smaller because it will result only from the diurnal asymmetry in the skin temperature. Note that locally the 01:30 and 13:30 RE can vary by more than $1.5 \mathrm{~W} / \mathrm{m}^{2}$ over arid regions such as the Sahara and portions of Australia and South Africa. Again, to alleviate potential biases in a comparison with model output, the model could be sampled at the Aqua overpass times.

The tropospheric $\mathrm{O}_{3}$ mixing ratios were derived in the UV assuming a uniform profile. Therefore, to be consistent, we use a uniform profile for SW calculations. However, LW calculations are much more sensitive to the assumed $\mathrm{O}_{3}$ distribution. Therefore, for LW calculations we use the derived tropospheric $\mathrm{O}_{3}$ column between the tropopause and the effective pressure distributed using a daily profile shape from the Global Modeling Initiative (GMI) combo chemistry-transport model (Duncan et al., 2007). We examine the sensitivity of the computed LW RE to the assumed profile shape in more detail in Appendix B3.

\subsection{Daily long- and short-wave radiative effect}

Figure 5 shows the LW and SW total-sky tropospheric $\mathrm{O}_{3}$ RE for 1 July 2005 and the impact of clouds (total- minus clear-sky tropospheric $\mathrm{O}_{3} \mathrm{RE}$ ). High values of the LW RE occur over the Sahara and the middle East as noted in previous works. This is understood to occur because of the high surface skin temperatures during the day coupled with low humidity, low cloud amounts, and large column amounts of $\mathrm{O}_{3}$ as discussed by $\mathrm{Li}$ et al. (2001). The lowest LW RE values occur, as expected, in the presence of high clouds (e.g., areas of tropical deep convection). High values of SW RE are concentrated in the northern hemisphere as a result of the larger amount of solar irradiance and tropospheric ozone and primarily occur over clouds or high albedo surfaces such as Greenland and the Sahara.

The cloud effect is primarily to reduce the LW RE. However, in a few areas with low clouds and temperature inversions, clouds can increase the LW RE. Examples of this situation include areas off the western coasts of North America and southern Africa as well as in the Arctic.

\subsection{Monthly-mean long-wave radiative effect}

Figure 6 shows the gridded monthly-mean total-sky LW RE for January and July 2005 and the impact of clouds. Most of the fine spatial features seen in the daily RE have been smoothed out in the monthly mean. In the winter hemisphere, where surface temperatures are cold over land, the LW RE is small and the effect of clouds is generally small or even slightly positive. Over oceans, where surface temperatures can be warmer such as in the gulf stream, clouds can significantly reduce the LW RE. In the summer hemisphere, 

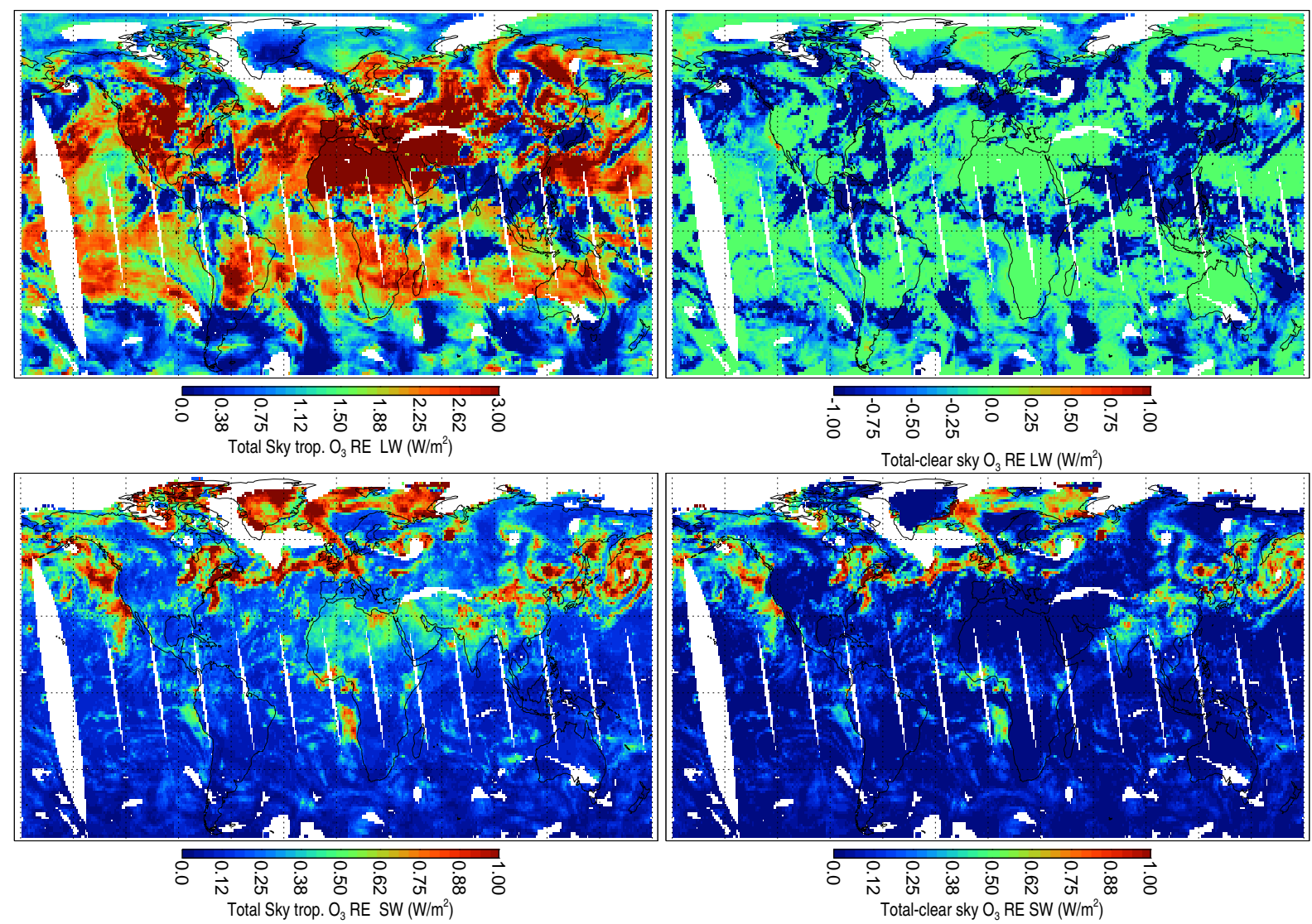

Fig. 5. Instantaneous (unadjusted) daily-averaged total-sky tropospheric $\mathrm{O}_{3}$ radiative effect (RE): long-wave (top left) and short-wave (bottom left); Total minus clear-sky RE: long-wave (top right) and short-wave (bottom right) on 1 July 2005.

land surface temperatures can be quite warm, giving rise to a large RE in the absence of clouds and a large impact of clouds when present (e.g., over India).

Figure 7 shows the total-sky sensitivity of LW RE (in $\mathrm{mW} / \mathrm{m}^{2}$ per ppb change in the column-mean $\mathrm{O}_{3}$ mixing ratio) for January and July 2005. Note that this sensitivity also applies to the unadjusted radiative forcing. The computed LW RE bears a close resemblance to this sensitivity, with a few exceptions. The RE is low over substantial areas in the Pacific, while the sensitivity there is not always small. This is primarily due to low $\mathrm{O}_{3}$ mixing ratios that result from the lofting of ozone-poor boundary layer air that occurs during convection and outflow. These low mixing ratios can persist for some time so that even when the sensitivity is relatively high, the RE remains low.

\subsection{Monthly-mean short-wave radiative effect}

Figure 8 shows the SW RE and cloud impact for January and July 2005. The highest values of SW RE in the northern hemisphere in January occur over southeast Asia. These high amounts of SW RE are primarily due to clouds. In order to obtain these high values, the clouds must be persistent and bright. MODIS data show that the effective radii over this region are small. However, these small values are not uncommon over land in the northern hemisphere. MODIS data also show the highest liquid water cloud fractions in the northern hemisphere over this area. Correlations between aerosols produced with models and observed cloud optical depths and a corresponding anti-correlation with effective radii suggest that aerosol indirect effects contribute to this feature (e.g., Chameides et al., 2002; Kawamoto et al., 2004). Aside from this area, the highest values of SW RE occur in coastal and low lying terrain areas of Antarctica where the bright surface enhances the photon pathlength.

There are large values of the SW RE over Greenland and arctic sea ice in July. We are reasonably confident in these derived values as the total measured column $\mathrm{O}_{3}$ is accurately retrieved over bright surfaces when the solar zenith angles are not high enough to produce significant profile shape sensitivity $\left(<\sim 80^{\circ}\right)$. As stated above, the column-mean tropospheric $\mathrm{O}_{3}$ mixing ratio, and likewise its associated radiative effect, may be underestimated over snow/ice when optically thick clouds are present. We have found that the sensitivity of ozone absorption to clouds is relatively small for the brightest surfaces (Greenland and Antarctica) for low to moderate 

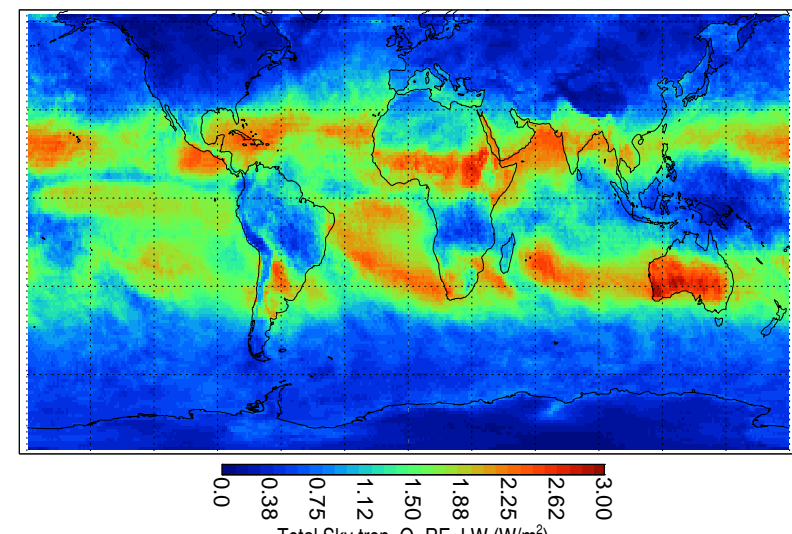

Total Sky trop. $\mathrm{O}_{3} \mathrm{RE} \operatorname{LW}\left(\mathrm{W} / \mathrm{m}^{2}\right)$

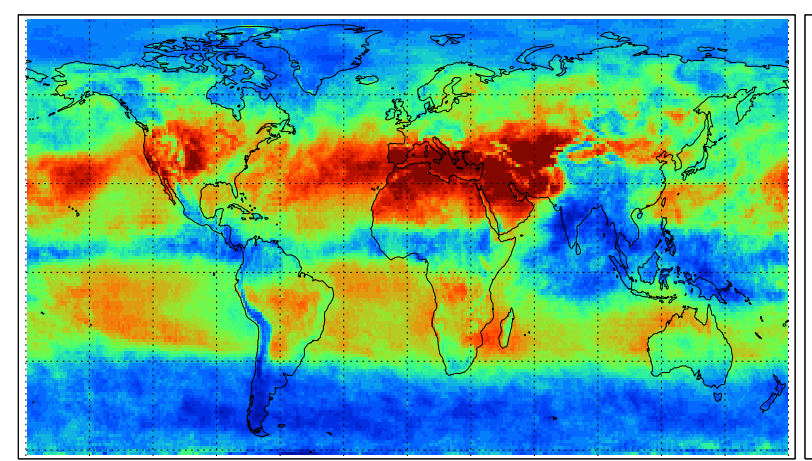

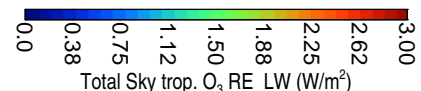

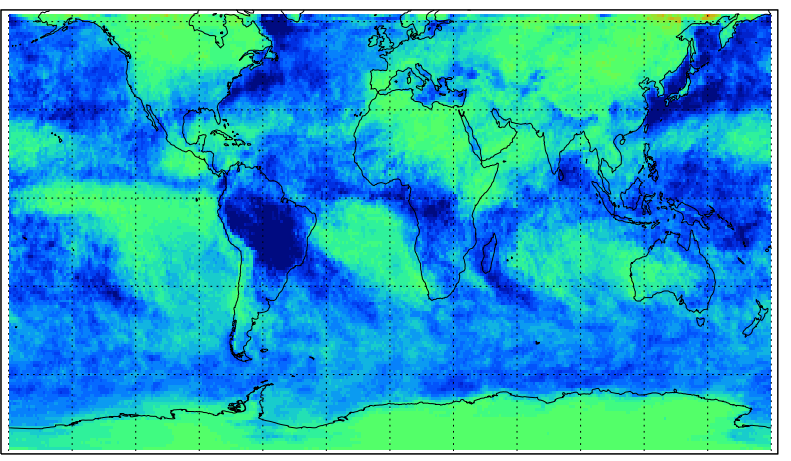

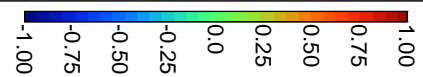

Total-clear sky $\mathrm{O}_{3} \mathrm{RE} \mathrm{LW}\left(\mathrm{W} / \mathrm{m}^{2}\right)$
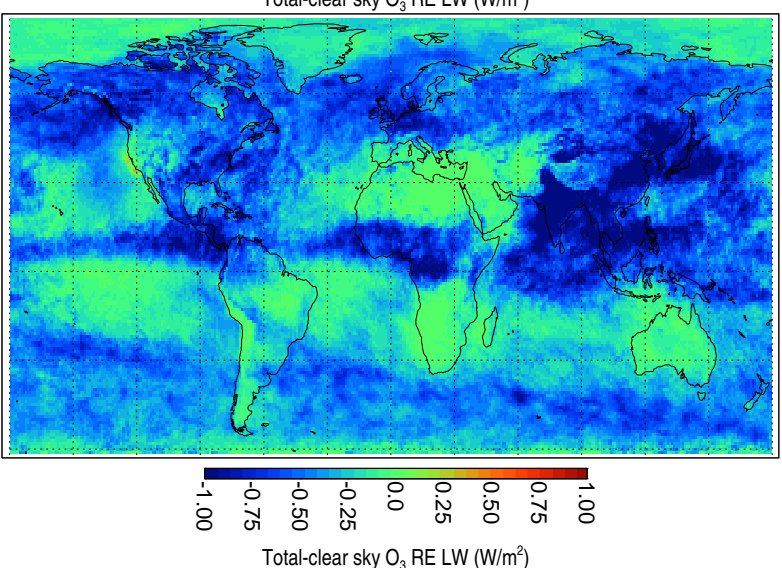

Fig. 6. Total-sky long-wave (LW) tropospheric $\mathrm{O}_{3}$ RE in 2005: January (top left) and July (bottom left); total minus clear-sky LW RE: January (top right) and July (bottom right).
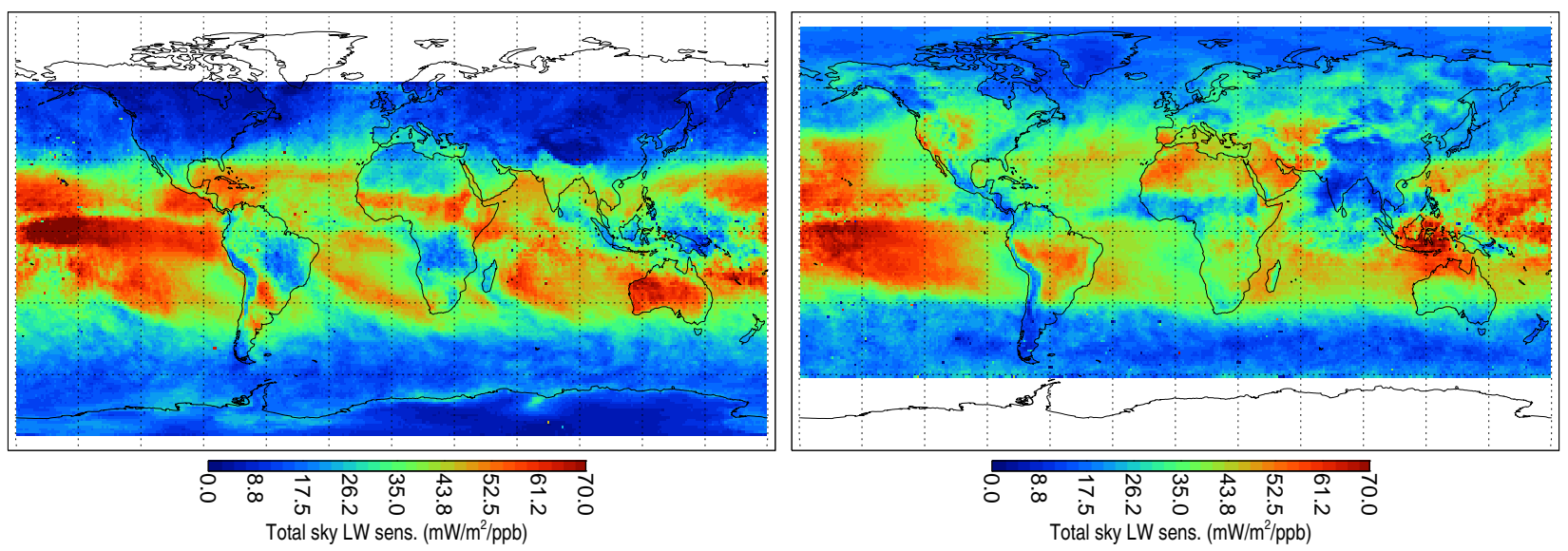

Fig. 7. Sensitivity of the LW RE to ozone mixing ratio for January (left) and July (right) 2005. 

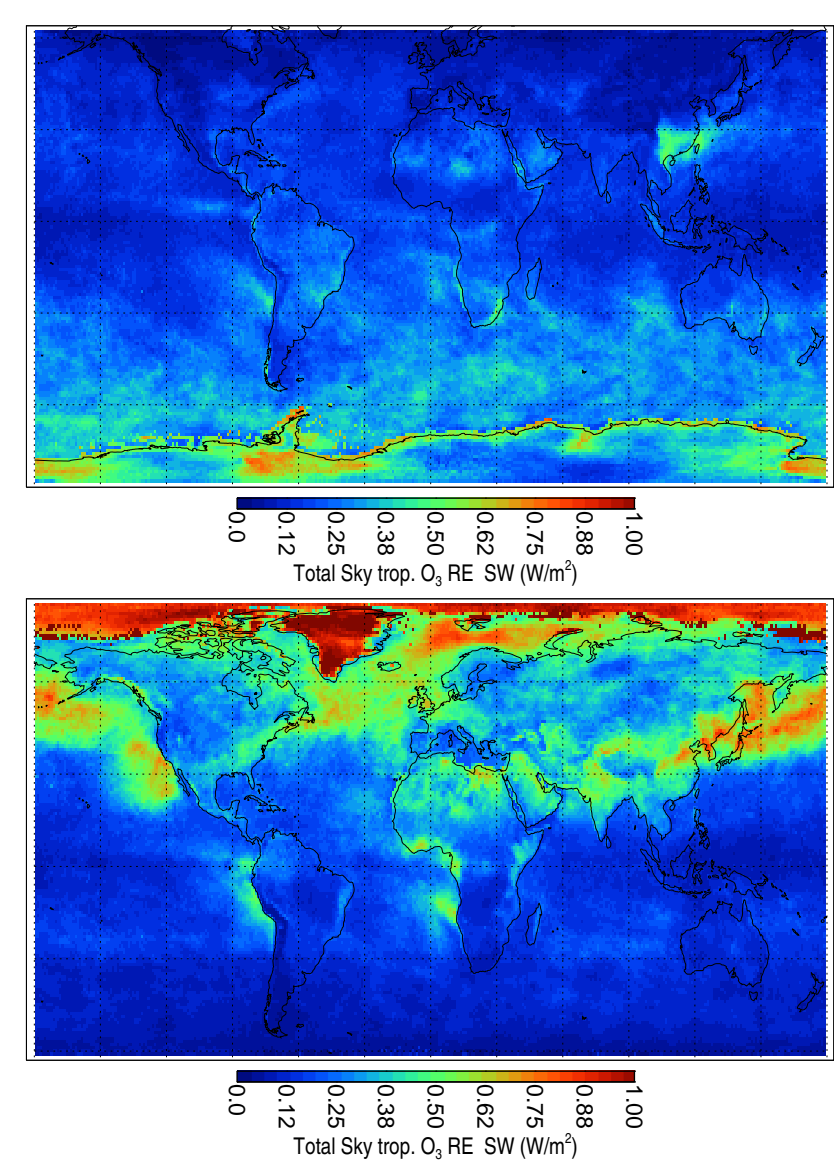
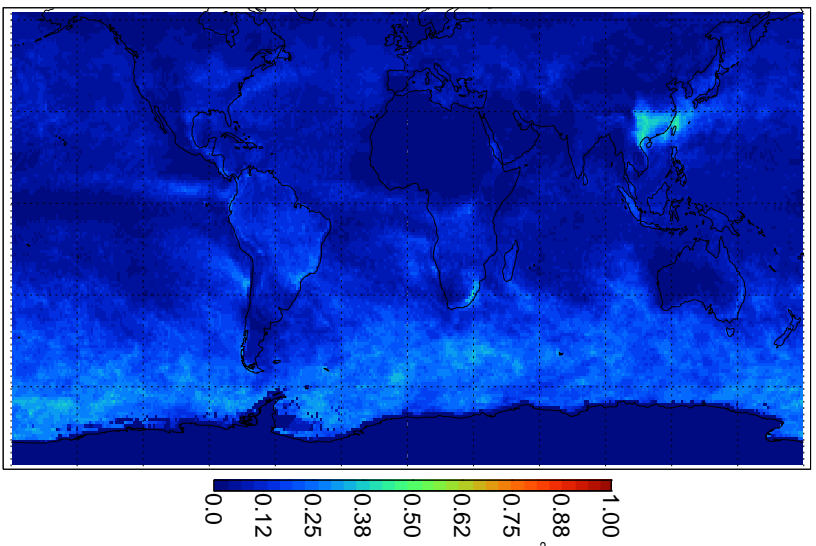

Total-clear sky $\mathrm{O}_{3} \mathrm{RE}$ SW $\left(\mathrm{W} / \mathrm{m}^{2}\right)$
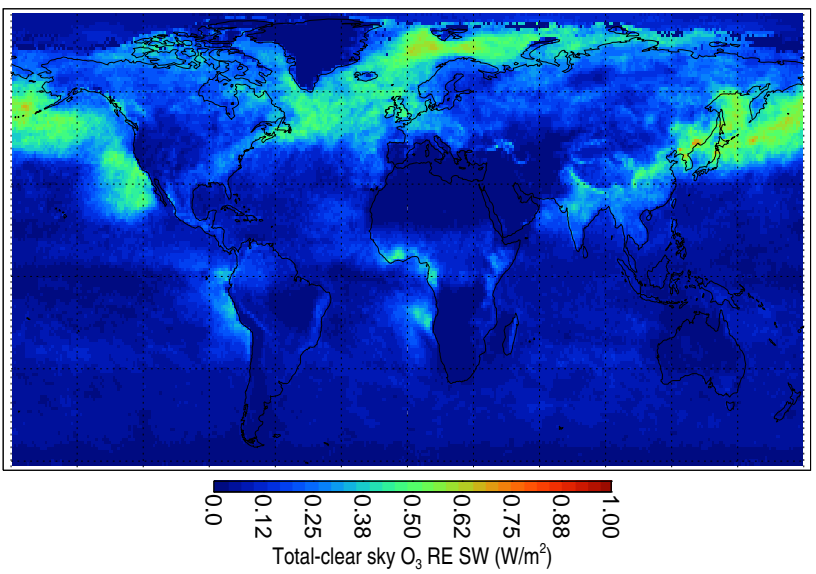

Fig. 8. Total-sky short-wave (SW) tropospheric $\mathrm{O}_{3} \mathrm{RE}$ in 2005: January (top left) and July (bottom left); total minus clear-sky SW RE: January (top right) and July (bottom right).
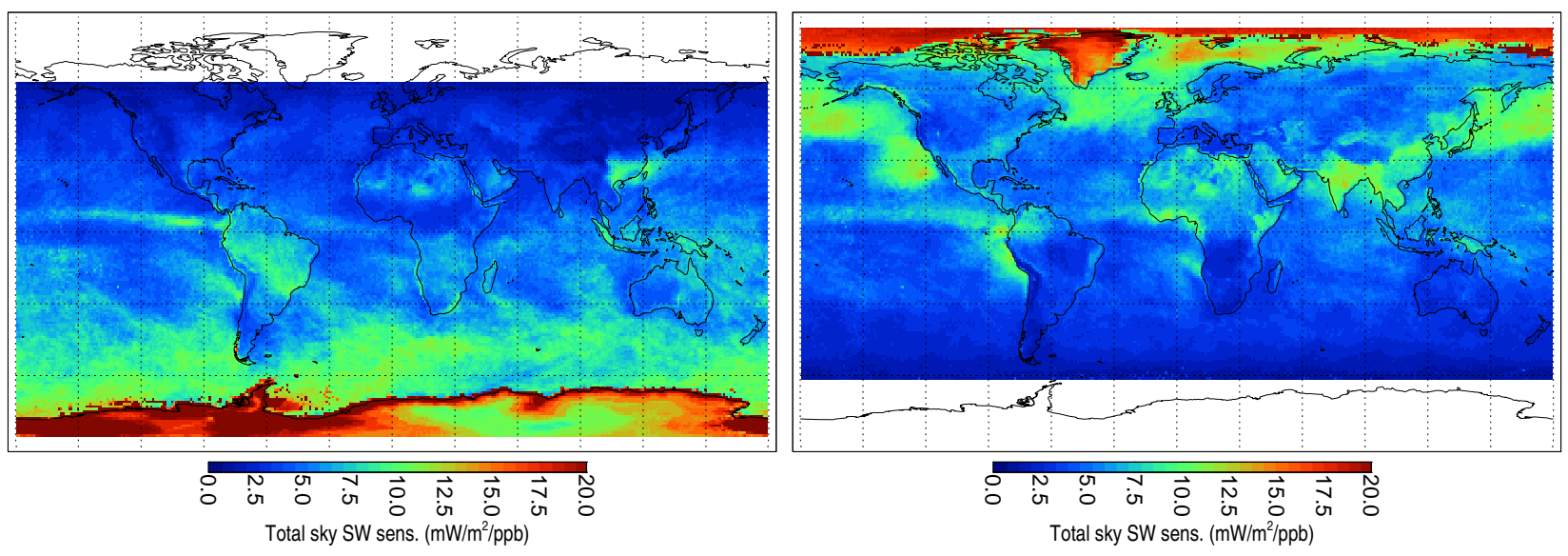

Fig. 9. Sensitivity of the SW RE to ozone mixing ratio for January (left) and July (right) 2005. 
Table 1. Computed LW/SW global and zonal mean tropospheric $\mathrm{O}_{3} \mathrm{RE}\left(\mathrm{W} / \mathrm{m}^{2}\right)$ and sensitivity (W/m²/ppb) for 2005 with standard deviations in parentheses.

\begin{tabular}{lrrrrrr}
\hline & $\begin{array}{r}\text { LW RE } \\
\text { total }\end{array}$ & $\begin{array}{r}\text { LW RE } \\
\text { total-clear }\end{array}$ & $\begin{array}{r}\text { LW sens. } \\
\text { total }\end{array}$ & $\begin{array}{r}\text { SW RE } \\
\text { total }\end{array}$ & $\begin{array}{r}\text { SW RE } \\
\text { total-clear }\end{array}$ & $\begin{array}{r}\text { SW sens. } \\
\text { total }\end{array}$ \\
\hline January $90^{\circ} \mathrm{S}-60^{\circ} \mathrm{N}$ & $1.14(0.60)$ & $-0.37(0.23)$ & $31.7(17.6)$ & $0.19(0.12)$ & $0.09(0.08)$ & $5.7(4.7)$ \\
January $20^{\circ} \mathrm{S}-20^{\circ} \mathrm{N}$ & $1.40(0.50)$ & $-0.40(0.25)$ & $43.0(16.3)$ & $0.16(0.05)$ & $0.06(0.04)$ & $5.3(1.4)$ \\
January $20^{\circ} \mathrm{N}-60^{\circ} \mathrm{N}$ & $0.87(0.53)$ & $-0.34(0.26)$ & $20.3(15.2)$ & $0.13(0.06)$ & $0.06(0.05)$ & $3.1(1.3)$ \\
January $20^{\circ} \mathrm{S}-60^{\circ} \mathrm{S}$ & $1.26(0.55)$ & $-0.40(0.15)$ & $33.0(12.9)$ & $0.26(0.06)$ & $0.15(0.07)$ & $7.2(1.7)$ \\
January $60^{\circ} \mathrm{S}-90^{\circ} \mathrm{S}$ & $0.44(0.17)$ & $-0.27(0.19)$ & $15.3(5.4)$ & $0.38(0.13)$ & $0.12(0.12)$ & $13.6(5.2)$ \\
July $60^{\circ} \mathrm{S}-90^{\circ} \mathrm{N}$ & $1.48(0.62)$ & $-0.42(0.25)$ & $33.5(13.2)$ & $0.24(0.22)$ & $0.11(0.13)$ & $5.2(3.9)$ \\
July $20^{\circ} \mathrm{S}-20^{\circ} \mathrm{N}$ & $1.48(0.47)$ & $-0.42(0.29)$ & $41.8(12.6)$ & $0.18(0.08)$ & $0.08(0.06)$ & $5.3(1.6)$ \\
July 20 $\mathrm{N}-60^{\circ} \mathrm{N}$ & $1.97(0.61)$ & $-0.49(0.29)$ & $33.6(10.6)$ & $0.38(0.14)$ & $0.19(0.15)$ & $6.5(2.3)$ \\
July $20^{\circ} \mathrm{S}-60^{\circ} \mathrm{S}$ & $1.08(0.47)$ & $-0.36(0.15)$ & $26.3(10.3)$ & $0.12(0.04)$ & $0.05(0.02)$ & $2.9(0.9)$ \\
July $60^{\circ} \mathrm{N}-90^{\circ} \mathrm{N}$ & $1.08(0.27)$ & $-0.40(0.20)$ & $19.5(4.4)$ & $0.52(0.25)$ & $0.22(0.14)$ & $9.6(5.2)$ \\
\hline
\end{tabular}

Table 2. Computed net (LW+SW) global and zonal mean tropospheric $\mathrm{O}_{3} \mathrm{RE}\left(\mathrm{W} / \mathrm{m}^{2}\right)$ and sensitivity (mW/m²/ppb) for 2005 .

\begin{tabular}{|c|c|c|c|c|c|}
\hline & $\begin{array}{r}\text { Net RE } \\
\text { total }\end{array}$ & $\%$ LW RE & $\begin{array}{r}\text { Net RE } \\
\text { total-clear }\end{array}$ & $\begin{array}{r}\% \text { Net RE } \\
\text { (total-clear)/clear }\end{array}$ & $\begin{array}{r}\text { Net sens. } \\
\text { total }\end{array}$ \\
\hline January $90^{\circ} \mathrm{S}-60^{\circ} \mathrm{N}$ & 1.33 & 85.7 & -0.28 & -17.4 & 37.4 \\
\hline January $20^{\circ} \mathrm{S}-20^{\circ} \mathrm{N}$ & 1.56 & 89.7 & -0.34 & -17.9 & 48.3 \\
\hline January $20^{\circ} \mathrm{N}-60^{\circ} \mathrm{N}$ & 1.00 & 87.0 & -0.28 & -21.8 & 23.4 \\
\hline January $20^{\circ} \mathrm{S}-60^{\circ} \mathrm{S}$ & 1.52 & 82.9 & -0.25 & -14.1 & 40.2 \\
\hline January $60^{\circ} \mathrm{S}-90^{\circ} \mathrm{S}$ & 0.82 & 53.6 & -0.15 & -15.5 & 28.9 \\
\hline July $60^{\circ} \mathrm{S}-90^{\circ} \mathrm{N}$ & 1.72 & 86.0 & -0.31 & -15.3 & 38.7 \\
\hline July $20^{\circ} \mathrm{S}-20^{\circ} \mathrm{N}$ & 1.66 & 89.2 & -0.34 & -17.0 & 47.1 \\
\hline July $20^{\circ} \mathrm{N}-60^{\circ} \mathrm{N}$ & 2.35 & 83.8 & -0.30 & -11.3 & 40.1 \\
\hline July $20^{\circ} \mathrm{S}-60^{\circ} \mathrm{S}$ & 1.20 & 90.0 & -0.31 & -20.5 & 29.2 \\
\hline July $60^{\circ} \mathrm{N}-90^{\circ} \mathrm{N}$ & 1.60 & 67.5 & -0.18 & -10.1 & 29.1 \\
\hline
\end{tabular}

cloud optical thickness $(<\sim 20)$. Note that Greenland and Antarctica typically have surface reflectivities of well over $90 \%$.

There are also high values of SW RE in areas with persistent cloud cover and high amounts of tropospheric $\mathrm{O}_{3}$, such as off the east coast of Asia, both coasts of North America, and north of Europe. Despite the lack of cloudiness over the Sahara, there is considerable SW RE due to its relatively high surface albedo. Off the west coasts of South America and Africa, clouds are prevalent along with moderate to high amounts of tropospheric $\mathrm{O}_{3}$, leading to significant amounts of SW RE.

Figure 9 shows the SW RE sensitivity similar to Fig. 7. Although the SW sensitivity is relatively high in the southern middle to high latitudes in January, the SW RE is low due to relatively low amounts of tropospheric $\mathrm{O}_{3}$. In July, however, high sensitivity in the Arctic coupled with relatively high tropospheric $\mathrm{O}_{3}$ produces a significant amount of SW RE.

\section{Discussion}

Global (excluding polar night regions) and zonal mean values of LW and SW RE and corresponding sensitivities are summarized in Table 1 . Values of the net $(\mathrm{LW}+\mathrm{SW}) \mathrm{RE}$ and sensitivity are given in Table 2. A cosine latitude weighting is applied to calculate the mean values. On a global mean basis, the clouds reduce the LW RE by $23 \%$, while they nearly double the SW RE. The reduction in the net RE is about $16 \%$. However, as can be seen in Table 2, there are large variations in cloud effects due to the partitioning between LW and SW that changes with solar zenith angle.

Portmann et al. (1997) computed sensitivities in terms of column amount rather than mixing ratio for clear skies. They showed that for several tropical locations the radiative forcing was relatively constant (to within $\sim 20 \%$ ) throughout the year. Here, we show that clouds significantly affect the sensitivity both spatially and temporally. Our sensitivity results show reasonable agreement with those presented in Berntsen et al. (1997) especially considering that the horizontal resolution of their CTM was relatively low $\left(8^{\circ} \times 10^{\circ}\right)$. 
As expected, our satellite-based estimates show finer spatial structures. However, even after accounting for the fact that their sensitivity was computed with stratospheric adjustment, our global mean values are higher: $38 \mathrm{~mW} / \mathrm{m}^{2} / \mathrm{ppb}$ as compared with theirs $\left(20 \mathrm{~mW} / \mathrm{m}^{2} / \mathrm{ppb}\right.$ and similar values reported in Hauglustaine and Brasseur, 2001).

The most recent IPCC report provides an estimated value of radiative forcing (after stratospheric adjustment) due to anthropogenic tropospheric ozone of $+0.35(-0.1,+0.3)$ $\mathrm{W} / \mathrm{m}^{2}$ (Forster et al., 2007). This estimate is the median of the adjusted radiative forcing derived from an ensemble of CTMs/GCMs. The reported uncertainties arise from two sources: (1) The CTMs and GCMs themselves, including the imbedded radiative transfer codes, and (2) uncertainties in the estimated pre-industrial ozone levels.

In Table 3, we compare several model-based radiative forcing (RF) estimates that used various observational constraints. Note that some of these are older simulations and were not included in the most recent reported IPCC estimate. Also, note that all table entries, excepting the IPCC ensemble mean, are unadjusted (instantaneous) calculations as are ours. Mickley et al. (2001) adjusted the emissions of ozone precursors in their model to bring pre-industrial ozone concentrations into better agreement with surface observations over Europe from late nineteenth and early twentieth observations (7-10 ppb). These observations have a large uncertainty related to potential calibration problems (e.g., Volz and Kley, 1988; Pavelin et al., 1999). The resulting radiative forcing was significantly higher $\left(0.72-0.80 \mathrm{~W} / \mathrm{m}^{2}\right)$ than the typical range produced by standard model runs. This contributes to the large uncertainty in the positive direction in the current IPCC report.

Kiehl et al. (1999) constrained their present-day tropospheric ozone estimates with satellite data. They used tropospheric columns from the residual approach of Fishman and Brackett (1997). In that work, the stratospheric column was derived from averages of several years of Stratospheric Aerosol and Gas Experiment (SAGE) occultation data and the total column was from the version 7 TOMS. This yielded data between $50^{\circ} \mathrm{S}$ and $50^{\circ} \mathrm{N}$ that were accurate to approximately $20 \%$ when compared with ozonesonde data. Model-generated cloud fractions were constrained such that the global mean cloud cover agreed with that from the International Satellite Cloud Climatology Project (ISCCP). They computed an unadjusted RF value of $1.55 \mathrm{~W} / \mathrm{m}^{2}$ assuming a preindustrial $\mathrm{O}_{3}$ mixing ratio of $5 \mathrm{ppb}$ at all tropospheric altitudes.

Berntsen et al. (1997) used cloud amounts, cloud levels, and optical depths from ISCCP. They similarly imposed observational constraints on present-day $\mathrm{O}_{3}$ distributions using data from TOMS, SBUV, and SAGE (in the Reading model). They used a CTM to compute the absolute $\mathrm{O}_{3}$ changes over the industrial era. They also computed the RF from pure $\mathrm{CTM} \mathrm{O}_{3}$ distributions (OsloRad). The resulting difference in unadjusted clear-sky LW RF (20\%) indicates that uncertainty in the present-day $\mathrm{O}_{3}$ distributions also contributes to the overall uncertainty in RF. Their computed RF, after stratospheric adjustment, is slightly below the IPCC median. It is roughly half that of the high values of Mickley et al. (2001) and roughly a quarter of the upper limits reported in Kiehl et al. (1999) and our study.

Our January-July RE average $\left(1.53 \mathrm{~W} / \mathrm{m}^{2}\right)$ is slightly lower than the RF cited in Kiehl et al. (1999), noting that we are not comparing identical quantities (we include the total column tropospheric ozone - equivalent to using a preindustrial value of $0 \mathrm{ppb}$ while they used a pre-industrial value of $5 \mathrm{ppb}$ ). Our RE is well above the RF from Mickley et al. (2001) $\left(0.8 \mathrm{~W} / \mathrm{m}^{2}\right)$ that represents the highest modelbased estimate of RF. Again, it must be noted that RF includes only the anthropogenic tropospheric $\mathrm{O}_{3}$.

Table 4 summarizes reported estimates of the cloud impact on RF and RE. All results shown are unadjusted (instantaneous) calculations. Roelofs (1999) demonstrated the importance of using instantaneous rather than monthly mean cloud properties, especially for SW RF calculations as noted in the table. The SW cloud effects are highly variable with our results falling in the middle of those reported earlier using either purely model-based clouds or clouds constrained by satellite data. We note that the treatment of cloud overlap varied in the model-based studies. The difference in the SW results appears to have been significantly influenced by the assumed surface albedo as Roelofs (1999) showed larger variations in the reported clear-sky RF from the different studies than in the total-sky. Similarly, there is a larger variation in the clear-sky LW RF than in the total-sky. This appears to be primarily due to differences in the $\mathrm{O}_{3}$ distribution. Our LW and net cloud impacts fall in the middle of the distribution of reported results.

We can compare our monthly tropospheric $\mathrm{O}_{3}$ and $\mathrm{RE}$ with similar seasonal maps shown in previous works (e.g., Mickley et al., 1999, 2004; Wong et al., 2004; Roelofs et al., 1997; van Dorland et al., 1997). In Mickley et al. (1999), the preindustrial ozone mixing ratio at $500 \mathrm{hPa}$ displayed little longitudinal variability. Therefore, we may qualitatively compare the longitudinal variability of the model-based RF with our RE. Note that their results were also reported in terms of unadjusted calculations.

We find many similar spatial and temporal features in the LW RF and RE, but also some notable differences. Both models and satellite data show high tropospheric $\mathrm{O}_{3}$ mixing ratios and RE/RF in the southern hemisphere off the African coasts and in the northern hemisphere middle latitudes in July. Our satellite-based estimates show high LW RE over Australia in January whereas the model results are relatively lower. This may be due to higher surface skin temperatures in the GEOS-5 assimilated data set.

We also have a consistently larger area of low RE over the Pacific. The extent of the low $\mathrm{O}_{3}$ mixing ratios derived by the OMI/MLS residual technique in this region are not well produced in any of the models. We have lower relative 
Table 3. Computed net $(\mathrm{LW}+\mathrm{SW}) \mathrm{RE}$ and radiative forcing $(\mathrm{RF})\left(\mathrm{W} / \mathrm{m}^{2}\right)$. Values are instantaneous (not adjusted) $\mathrm{RF}$ (from anthropogenically-produced tropospheric $\mathrm{O}_{3}$ ) unless otherwise noted.

\begin{tabular}{|c|c|c|}
\hline Reference & $\mathrm{RF} / \mathrm{RE}$ & Ozone, Cloud data sources \\
\hline IPCC $^{\mathrm{a}}$ & $0.35(-1,+0.3)$ & model clouds \\
\hline Kiehl et al. (1999) & 1.55 & $\begin{array}{l}\mathrm{RF} \text { is median of an ensemble of models } \\
\text { model clouds constrained to } \\
\text { ISCCP cloud amount } \\
\text { present-day } \mathrm{O}_{3} \text { constrained with satellite data } \\
\text { pre-industrial } \mathrm{O}_{3} 5 \mathrm{ppb}\end{array}$ \\
\hline Mickley et al. (2001) & $0.72-0.80$ & $\begin{array}{l}\text { model clouds } \\
\text { pre-industrial } \mathrm{O}_{3} \text { adjusted to } \\
\text { uncertain surface observations }\end{array}$ \\
\hline Berntsen et al. (1997, Reading) & 0.35 & $\begin{array}{l}\text { ISCCP cloud properties } \\
\text { present-day } \mathrm{O}_{3} \text { distributions } \\
\text { constrained with satellite data } \\
\text { absolute } \mathrm{O}_{3} \text { changes from CTM }\end{array}$ \\
\hline Berntsen et al. (1997, OsloRad) & 0.38 & $\begin{array}{l}\text { ISCCP cloud properties } \\
\mathrm{O}_{3} \text { distributions from CTM }\end{array}$ \\
\hline This work ${ }^{b}$ & 1.53 & satellite-based clouds and $\mathrm{O}_{3}$ \\
\hline
\end{tabular}

\footnotetext{
a Stratospheric-adjusted, not instantaneous

b January-July average, polar night region excluded, anthropogenic+natural $\mathrm{O}_{3}$.
}

Table 4. Computed impact of clouds on RF/RE (unadjusted, anthropogenic RF unless otherwise noted) (total-sky - clear-sky)/clearsky $\times 100(\%)$.

\begin{tabular}{lrrrr}
\hline Reference & LW (\%) & SW (\%) & Net (\%) & cloud source \\
\hline Roelofs (1999, inst. clouds) & -24 & 125 & -10 & model \\
Roelofs (1999, avg. clouds) & -19 & 150 & -2 & model \\
Hauglustaine and Brasseur (2001) & -18 & 50 & -10 & model \\
Berntsen et al. (1997, Reading) & -20 & 40 & -13 & ISCCP \\
Berntsen et al. (1997, OsloRad) & -29 & 33 & -21 & ISCCP \\
Haywood et al. (1998, inst. clouds) & -30 & 250 & -17 & model \\
Haywood et al. (1998, avg. clouds) $_{\text {This work }}^{\mathrm{a}}$ & -31 & 150 & -22 & model \\
& -23 & 87 & -16 & MODIS/OMI \\
\hline
\end{tabular}

a January-July average, polar night region excluded, RE from anthropogenic+natural $\mathrm{O}_{3}$

amounts of RE in this area than the model-based estimates of RF. Our approach also produces relatively lower amounts of $\mathrm{RE}$ in the high latitudes during summer than in the RF of Mickley et al. (1999, 2004), indicating that those modelbased RF estimates are too high.

In the SW, our high RE over southeast Asia in January is not reproduced in the RF map of Mickley et al. (1999), indicating that the cloudiness responsible for the high values is not present in their model. We find higher amounts of SW $\mathrm{RE}$ at middle latitudes relative to the Arctic as compared with the RF in Mickley et al. (1999) and Wong et al. (2004). This suggests that the models may not be producing enough SW RF in cloudy regions. This is particularly apparent in the north Atlantic and north Pacific as well as off the west coast of North America where there are persistent marine stratocumulus.

\section{Conclusions}

We have improved estimates of daily tropospheric $\mathrm{O}_{3}$ mixing ratios in cloudy areas by using optical centroid cloud pressures (OCCP) from OMI. We derived column-mean mixing ratios that correspond to a thick tropospheric layer between the tropopause and an effective pressure that can be computed using the OMI cloud fraction and OCCP.

We have computed the present day radiative effect due to tropospheric $\mathrm{O}_{3}$ using, to our knowledge, the most accurate daily global satellite data available to date consisting of several coincident datasets from the A-train. Our approach provides improved temporal and spatial coverage and a more detailed account of cloud effects than previous efforts that utilized satellite data exclusively.

We note that it is important to have coincident retrievals of appropriate cloud properties and tropospheric ozone. In unpolluted oceanic areas (e.g., the remote Pacific), $\mathrm{O}_{3}$ mixing ratios inside and above clouds can be very low, leading to low values of both LW and SW RE. However, in polluted regions, $\mathrm{O}_{3}$ mixing ratios can be relatively large inside and above clouds. This can lead to significant amounts of LW and SW RE over low lying clouds and also large amounts of SW RE in convective clouds.

Though our definition of RE is not the same as the common definition of RF used in IPCC reports, various aspects 
of our satellite-derived RE may be compared with modelbased RF estimates in an appropriate way. For example, our sensitivities of RE to ozone mixing ratio may be compared directly with model-based RF sensitivities; our values are somewhat higher than those reported from models. We show that satellite-derived and model-based cloud impacts are relatively consistent in the global mean net (our impact is $16 \%$ with model estimates in the range 2-22\%), though the model results were highly variable in the cloud-sensitive SW. Note again that our results are reported in terms of unadjusted (instantaneous) calculations as were most of the results that we provided comparisons with.

Models capture seasonal and longitudinal variations in the RF reasonably well, though we were able to identify a few problematic regions. For example, most models do not reproduce the extent of the area of low ozone mixing ratios in the tropical Pacific.

We plan to conduct more direct model comparisons in the future. For those who are interested in using our satellitederived tropospheric ozone directly, the data are freely available for download (contact mark.r.schoeberl@ nasa.gov).

\section{Appendix A}

\section{Chou-Suarez radiative transfer code}

In the SW CS code, the spectrum is divided into 8 bands in the ultraviolet (UV) and photosynthetically active (PAR) regions with a single ozone absorption coefficient and Rayleigh scattering coefficient in each band. There are 3 bands in the SW infrared where the $k$-distribution method is employed. Ozone absorption is accounted for in nine short-wave bands. The band-mean ozone transmission function was computed as the extraterrestrial solar flux-weighted mean; the UV and PAR regions were divided into 127 narrow bands of width $\sim 0.003 \mu \mathrm{m}$ with ozone absorption coefficients as given in WMO (1986). Similarly, a mean effective Rayleigh scattering coefficient was computed for ten of the bands. Differences between fluxes computed at high spectral-resolution and the parameterization were typically small $(<2 \%)$ for ozone.

Reflection and transmission of cloud and aerosol layers are calculated using the $\delta$-Eddington approximation, and fluxes are computed with a two-stream adding model. Spectral data provided by $\mathrm{Fu}$ (1996) for ice clouds and Tsay et al. (1989) for water clouds are used to derive an effective band-mean single scattering albedo, extinction coefficient, and asymmetry factor.

Thermal IR calculations in the LW are divided into eight bands. In order to optimize the algorithm for both speed and accuracy, Planck-weighted flux transmittances for gaseous absorption are computed using three different approaches, dependent on the absorber and band. The $k$-distribution method with linear pressure scaling is used for water va- por bands. Pre-computed transmittance tables based on twoparameter scaling are used to compute $\mathrm{CO}_{2}$ and $\mathrm{O}_{3}$ absorption in 15 and $9.6 \mu \mathrm{m}$ bands, respectively, as well as for the three strongest water vapor bands. Water vapor continuum absorption is similarly computed using a one parameter scaling approach. Differences between these parameterizations and line-by-line calculations were generally less than $1 \%$, leading to errors much smaller than $1 \mathrm{~W} / \mathrm{m}^{2} . \mathrm{O}_{3}$ absorption is computed only in the $9.6 \mu \mathrm{m}$; weaker absorption in the $14 \mu \mathrm{m}$ spectral region is not included.

For all LW calculations, we used the so-called "high" option the CS code, which provides the highest degree of accuracy at increased computational cost. Calculations are performed in 36 fixed layers between 1000 and $0.01 \mathrm{hPa}$ as specified in the GEOS-5 pressure level data. A smaller number of layers is used when the surface pressure is less than $1000 \mathrm{hPa}$.

The CS code was configured to accept profiles of cloud optical depth, effective radius, and cloud fraction separately for liquid and ice clouds. Although the code can also accept profiles of rain, this option was not exercised here. We describe how MODIS data are used with these inputs below. For LW calculations, we multiply the visible optical depth by empirical factors of 2.13 and 2.56 for ice and liquid, respectively, following Minnis et al. (1993) and Rossow and Schiffer (1999).

Although aerosols can be included in the CS code, we have not included their effects here. Non-absorbing aerosol will generally increase SW RE/RF similar to the effect of clouds. Saharan dust absorbs in the $9.6 \mu \mathrm{m}$ band and can therefore decrease LW RE/RF. Dust can also contaminate infrared temperature retrievals or radiance assimilation if not properly accounted for (e.g., Weaver et al., 2003).

We compared RF computed with the CS code in a clearsky mid-latitude summer case with that from several other radiative transfer (RT) codes examined in the intercomparison of Shine et al. (1994) by using their supplied profile information. The CS-computed SW tropospheric $\mathrm{O}_{3} \mathrm{RF}$ was $0.0184 \mathrm{~W} / \mathrm{m}^{2}$ which is also somewhat lower than the ensemble mean $\left(0.022 \mathrm{~W} / \mathrm{m}^{2}\right)$, but well within the range of results $\left(0.017-0.031 \mathrm{~W} / \mathrm{m}^{2}, \sigma=0.0046 \mathrm{~W} / \mathrm{m}^{2}\right)$. The $\mathrm{LW} \mathrm{O} \mathrm{O}_{3} \mathrm{RF}$ from CS $\left(0.140 \mathrm{~W} / \mathrm{m}^{2}\right)$ was approximately $10 \%$ less than the mean of the ensemble of RT calculations for the case where tropospheric ozone was perturbed. Note that some of the RT models include the $14 \mu \mathrm{m}$ band while others (including CS) do not. This band contributes about $2 \%$ of the forcing in this case (Shine et al., 1994).

Differences in the $\mathrm{LW} \mathrm{O}_{3} \mathrm{RF}$ may occur due to differences in the assumed $\mathrm{O}_{3}$ absorption coefficients as well as differences in the specification of the water vapor continuum which significantly affects the computed top-of-theatmosphere (TOA) radiances and fluxes in the $9.6 \mu \mathrm{m}$ band (Joiner et al., 1998). CS uses the version CKD2.3 water vapor continuum model of Clough et al. (1989). 


\section{Appendix B}

\section{Sensitivity studies}

Here, we perform a series of sensitivity calculations on a single day (1 July 2005).

\section{B1 Sensitivity to cloud optical properties}

In the first experiment, we found very little sensitivity of the tropospheric $\mathrm{O}_{3} \mathrm{RE}$ to the input cloud phase which determines the parameterized values of the single scattering albedo, extinction coefficient, and asymmetry factor. We similarly found little sensitivity to the cloud effective radius. Therefore, for all subsequent calculations we use the MODIS daily gridbox mean effective radius rather than averaging over its histogram or joint histogram with cloud optical thickness. If there was a successful liquid water cloud retrieval within a gridbox, regardless of whether or not there was a successful ice cloud retrieval, we use the mean effective radius of the liquid water cloud retrievals and specify the phase as water. Otherwise, we assume the cloud to be ice and use the effective radius of the ice cloud retrievals.

Our RE calculations, as expected, show a non-linear dependence on the cloud optical thickness. We examined the differences in RE computed with gridbox the mean cloud optical thickness $(\bar{\tau})$ versus calculations performed over the distribution of cloud optical thicknesses and then appropriately averaged using the reported histograms (full $\tau$ ). Although Oreopoulos et al. (2007) have shown that the full $\tau$ approach is more appropriate for calculations of cloud radiative forcing, here the differences for tropospheric $\mathrm{O}_{3} \mathrm{RE}$ were small (of the order of $0.01 \mathrm{~W} / \mathrm{m}^{2}$ or less). Mean differences over the latitude range $45^{\circ} \mathrm{S}$ to $45^{\circ} \mathrm{N}$ are small $\left(<0.003 \mathrm{~W} / \mathrm{m}^{2}\right.$ with $\sigma<0.025 \mathrm{~W} / \mathrm{m}^{2}$ ) in both the $\mathrm{LW}$ and diurnally-averaged SW. All results shown here use the $\bar{\tau}$ formulation.

\section{B2 Sensitivity to cloud vertical structure}

We compared two different methods of vertically distributing the total cloud optical thickness: (1) Cloud distributed over a $100 \mathrm{hPa}$ layer centered at the lesser of the OMI optical centroid cloud pressure (OCCP) or the surface pressure minus $50 \mathrm{hPa}$ 2) Cloud distributed over a $100 \mathrm{hPa}$ layer with the top specified as the MODIS cloud-top pressure. As expected, differences in both the LW and SW have spatial patterns similar to the differences between the OMI OCCP and the MODIS cloud-top pressure shown in Fig. 4 with larger magnitudes in areas of high $\mathrm{O}_{3}$ mixing ratios.

There are differences in the SW local RE of $\sim 50 \%$ in regions of heavy convective cloud cover where the ozone mixing ratios are high. Comparable but slightly larger differences (in terms of percent) occur in the LW RE. Averaged globally, RE is $\sim 8 \%$ and $12 \%$ less when using the cloud-top pressure as compared with the OCCP for the LW and SW, respectively.

Here, we use the MODIS cloud top pressure for LW RE calculations. In the LW, TOA radiances saturate as the visible optical depth reaches values of $\sim 4$. For deep convective clouds, the appropriate pressure would be close to the cloud top pressure (see e.g., Ziemke et al., 2009). However, the use of the cloud top pressure for LW RE calculations will produce an underestimate if the optical depth of the upper cloud deck is less than about 4 .

We use the OMI OCCP for SW RE calculations as it more accurately accounts for $\mathrm{O}_{3}$ absorption in cloudy conditions (Ziemke et al., 2009). Note that enhanced SW absorption can occur in the presence of multiple cloud layers, particularly at low solar zenith angles and when the optical depth of the upper cloud deck is less than about 10. The use of the OMI OCCP accounts for this effect because the retrieved cloud pressure increases when enhanced absorption/scattering occurs (Vasilkov et al., 2008), though there will likely be a small residual error in a full flux calculation because the cloud pressure was derived at a particular viewing geometry.

\section{B3 Sensitivity to $\mathrm{O}_{3}$ profile}

Here, we examine the sensitivity to the assumed $\mathrm{O}_{3}$ distribution by computing the difference in LW RE using a profile from the GMI combo model as above and assuming a uniform mixing ratio. Both calculations use the satellite-derived tropospheric $\mathrm{O}_{3}$ column amount between the tropopause and the effective pressure. The differences for January and July 2005, shown in Fig. B1, are significant and average approximate $25 \%$ globally. There is also significant spatial variation in the sensitivity.

\section{B4 Sensitivity to tropopause definition}

The tropopause pressure affects the calculation of the tropospheric mixing ratio from Eq. (2) in two ways: The denominator (the pressure difference between the surface/cloud and tropopause) is larger for the lapse-rate tropopause and results in lower mixing ratios. However, the residual tropospheric column amount in the numerator will be larger for the higher lapse-rate tropopause. The latter effect dominates as derived column-mean mixing ratios are generally higher with the lapse rate definition.

The $\mathrm{SW} \mathrm{O}_{3} \mathrm{RE}$ depends primarily on the tropospheric column amount, which is nearly always larger for the lapse-rate tropopause definition. The global mean difference in computed SW RE using the two tropopause definitions (lapserate $-\mathrm{PV}$ ) was $6 \%$ with maximum differences of $\sim 70-90 \%$ in narrow regions where the tropopause gradient is steep.

The LW forcing is more sensitive to ozone and temperature profiles in the vicinity of the tropopause where the gradient of the net flux is large. The differences in $\mathrm{LW} \mathrm{O}_{3} \mathrm{RE}$ 

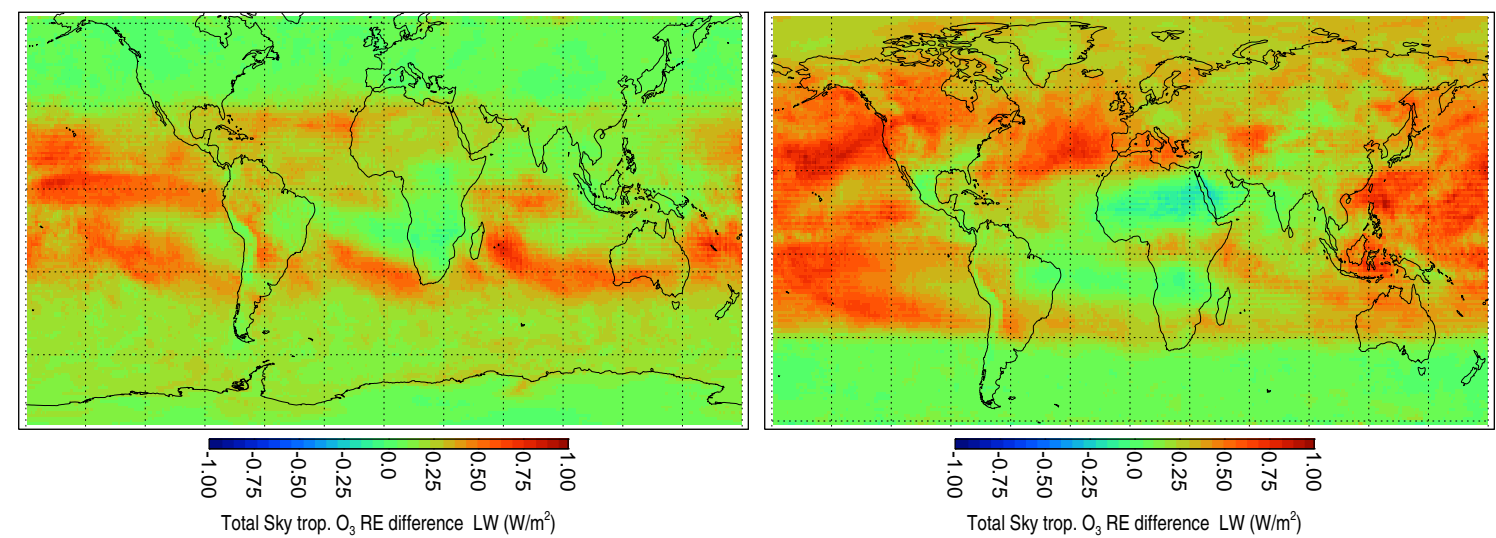

Fig. B1. Sensitivity of the LW RE to the assumed ozone profile shape (GMI profile - uniform mixing ratio) for January 2005 (left) and July 2005 (right).
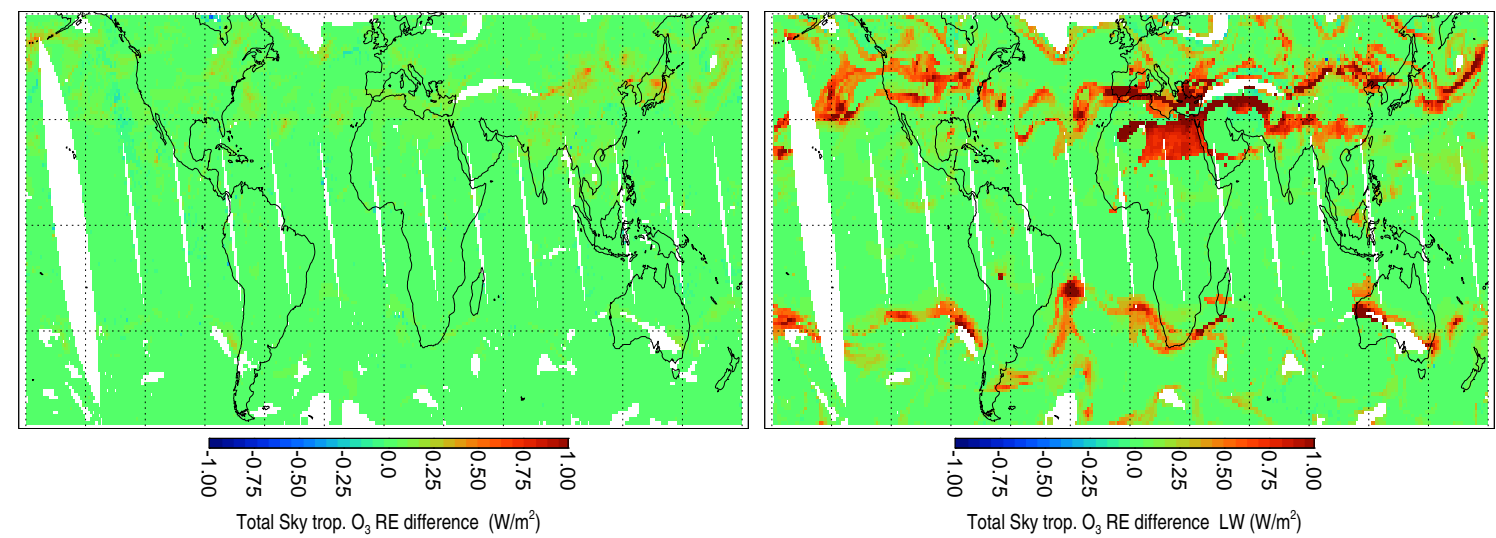

Fig. B2. Sensitivity of the RE to tropopause definition (lapse rate - PV) for 01 July 2005: SW (left) and LW (right).

resulting from different tropopause definitions are both positive and negative. Similar to the SW results, the global mean $\mathrm{LW}$ difference is $\sim 6 \%$ with local differences in the range $\sim \pm 70-90 \%$. An example of the daily mapped difference in the LW and SW RE in terms of $\mathrm{W} / \mathrm{m}^{2}$ resulting from the different tropopause definitions is shown in Fig. B2.

Acknowledgements. The authors thank the OMI, MLS, and MODIS science teams for the processing, validation, and distribution of data sets used here. The authors also thank two anonymous reviewers and the associate editor for helpful comments and suggestions. The lead author acknowledges helpful discussions with A. da Silva. This material is based upon work supported by NASA under agreement NNG06HX18C issued through the Science Mission Directorate for the Aura Science Team. Lazaros Oreopoulos gratefully acknowledges support for this work by the US Department of Energy, Office of Science, Office of Biological and Environmental Research, Environmental Sciences Division as part of the ARM program under grant DE-FG02-07ER64354. Work at the Jet Propulsion Laboratory, California Institute of Technology was performed under contract with NASA.

Edited by: A. Richter

\section{References}

Berntsen, T. K., Isaksen, I. S. A., Myhre, G., Fuglestvedt, J. S., Stordal, F. T., Larsen, A., Freckleton, R. S., and Shine, K. P.: Effects of anthropogenic emissions on tropospheric ozone and its radiative forcing, J. Geophys. Res., 102, 28 101-28 126, 1997.

Bhartia, P. K. and Wellemeyer, C. W.: TOMS-V8 total $\mathrm{O}_{3} \mathrm{Al}-$ gorithm, OMI Algorithm Theoretical Basis Document, vol. 2, edited by: Bhartia, P. K., Greenbelt, Md, http://toms.gsfc.nasa. gov/version8/v8toms_atbd.pdf, 2002.

Chameides, W. L., Luo, C., Saylor, R., Streets, D., Huang, Y., Bergin, M., and Giorgi, F.: Correlation between modelcalculated anthropogenic aerosols and satellite-derived cloud optical depths: Indication of indirect effect?, J. Geophys. Res., 107, 4085, doi:10.1029/2000JD000208, 2002.

Chou, M.-D. and Suarez, M. J.: An efficient thermal infrared radiation parameterization for use in general circulation models, NASA Tech. Memo 104606, 3, 85 pp., 1994.

Chou, M.-D. and Suarez, M. J.: A solar radiation parameterization for atmospheric studies, NASA Tech. Memo 104606, 15, 40 pp., 2002.

Chou, M.-D., Suarez, M. J., Liang, X.-A., and Yan, M. M.-H.: A thermal infrared radiation parameterization for atmospheric studies, NASA Tech. Memo 104606, 19, 85 pp., 2003. 
Clough, S. A., Kneizys, F. X., and Davies, R. W.: Line shape and the water vapor continuum, Atmos. Res., 23, 229-241, 1989.

Dessler, A.: The Chemistry and Physics of the Stratosphere, Elsevier, New York, p. 214, 2005.

Duncan, B. N., Strahan, S. E., Yoshida, Y., Steenrod, S. D., and Livesey, N.: Model study of the cross-tropopause transport of biomass burning pollution, Atmos. Chem. Phys., 7, 3713-3736, 2007 ,

http://www.atmos-chem-phys.net/7/3713/2007/.

van Dorland, R., Dentener, F., and Lelieveld, J.: Radiative forcing due to tropospheric ozone and sulfate aerosols, J. Geophys. Res., 102, 28 079-28 100, 1997.

Fishman, J. and Brackett, V.: The climatological distribution of tropospheric ozone derived from satellite measurements using version 7 Total Ozone Mapping Spectrometer and Stratospheric Aerosol and Gas Experiment data sets, J. Geophys. Res., 102, 19275-19278, 1997.

Folkins, I., Braun, C., Thompson, A. M., and Witte, J.: Tropical ozone as an indicator of deep convection, J. Geophys. Res., 107, 4184, doi:10.1029/2001JD001178, 2002.

Forster, P., Johnson, C., Law, K., Pyle, J., and Shine, K.: Further Estimates of Radiative Forcing Due to Tropospheric Ozone Changes, Geophys. Res. Lett., 23, 3321-3324, 1996.

Forster, P., Ramaswamy, V., Artaxo, P., et al.: Changes in atmospheric constituents and in radiative forcing, in: Climate Change 2007: The physical science basis. Contribution of working group I to the fourth assessment report of the intergovernmental panel on climate change, edited by: Solomon, S., Qin, D., Manning, M., et al., Cambridge Univ. Press, Cambridge, 2007.

Froidevaux, L., Jiang, Y. B., Lambert, A., et al.: Validation of Aura Microwave Limb Sounder stratospheric ozone measurements, J. Geophys. Res., 113, D15S20, doi:10.1029/2007JD008771, 2008.

Fu, Q.: An accurate parameterization of the solar radiative properties of cirrus clouds for climate models, J. Climate, 9, 20582082, 1996.

Gauss, M., Myhre, G., Isaksen, I. S. A., Grewe, V., Pitari, G., Wild, O., Collins, W. J., Dentener, F. J., Ellingsen, K., Gohar, L. K., Hauglustaine, D. A., Iachetti, D., Lamarque, F., Mancini, E., Mickley, L. J., Prather, M. J., Pyle, J. A., Sanderson, M. G., Shine, K. P., Stevenson, D. S., Sudo, K., Szopa, S., and Zeng, G.: Radiative forcing since preindustrial times due to ozone change in the troposphere and the lower stratosphere, Atmos. Chem. Phys., 6, 575-599, 2006,

http://www.atmos-chem-phys.net/6/575/2006/.

Hauglustaine, D. A. and Brasseur, G. P.: Evolution of tropospheric ozone under anthropogenic activities and associated radiative forcing of climate, J. Geophys. Res., 106, 32 337-32 360, 2001.

Haywood, J. M., Schwarzkopf, M. D., and Ramaswamy, V.: Estimates of radiative forcing due to modeled increases in tropospheric ozone, J. Geophys. Res., 103, 16999-17 007, 1998.

Jin, Z., Charlock, T., Smith, W., and Rutledge, K.: A parameterization of ocean surface albedo, Geophys. Res. Lett., 31, L22301, doi:10.1029/2004GL021180, 2004.

Joiner, J., Lee, H. T., Strow, L. L., Bhartia, P. K., Hannon, S., Miller, J., and Rokke, L.: Radiative transfer in the 9.6 micron HIRS ozone channel using collocated SBUV-determined ozone abundances, J. Geophys. Res., 103, 19213-19229, 1998.
Joiner, J., Vasilkov, A. P., Flittner, D. E., Gleason, J. F., and Bhartia, P. K.: Retrieval of cloud pressure and oceanic chlorophyll content using Raman scattering in GOME ultraviolet spectra, J. Geophys. Res., 109, D01109, doi:10.1029/2003JD003698, 2004.

Joiner, J. and Vasilkov, A. P.: First results from the OMI Rotational Raman Scattering Cloud Pressure Algorithm, IEEE T. Geosci. Remote, 44, 1272-1282, 2006.

Joiner, J., Vasilkov, A. P., Yang, K., and Bhartia, P. K.: Total column ozone over hurricanes from the Ozone Monitoring Instrument, Geophys. Res. Lett., 33, L06807, doi:10.1029/2005GL0255922006, 2006.

Kawamoto, K., Hayasaka, T., Nakajima, T., Streets, D., and Woo, J.-H.: Examining the aerosol indirect effect over China using an $\mathrm{SO}_{2}$ emission inventory, Atmos. Res., 72, 353-363, 2004.

Kiehl, J. T., Schneider, T. L., Portmann, R. W., and Solomon, S.: Climate forcing due to tropospheric and stratospheric ozone, J. Geophys. Res., 104, 31 239-31 254, 1999.

Kley, D., Crutzen, P. J., Smit, H. G. J., et al.: Observations of nearzero ozone concentrations over the convective Pacific: Effects on air chemistry, Science, 274, 230-233, 1996.

Kroon, M., Petropavlovskikh, I., Shetter, R. E., Hall, S., Ullmann, K., Veefkind, J. P., McPeters, R. D., Browell, E. V., and Levelt, P.: OMI Total Ozone Column Validation with Aura-AVE CAFS Observations, J. Geophys. Res., 113, D15S13, doi:10.1029/2007JD008795, 2008.

Kroon, M., Veefkind, J. P., Sneep, M., McPeters, R. D., Bhartia, P. K., and Levelt, P. F.: Comparing OMI-TOMS and OMIDOAS total ozone column data, J. Geophys. Res., 113, D16S28, doi:10.1029/2007JD008798, 2008.

Levelt, P. F., van den Oord, G. H. J., Dobber, M. R., et al.: The Ozone Monitoring Instrument, IEEE T Geosci. Remote, 44, 1093-1101, 2006.

Li, Q. B., Jacob, D. J., Logan, J. A., et al.: A tropospheric ozone maximum over the Middle East, Geophys. Res. Lett., 28, 32353238, 2001.

Livesey, N. J., Filipiak, M. J., Froidevaux, L., et al.: Validation of Aura Microwave Limb Sounder $\mathrm{O}_{3}$ and $\mathrm{CO}$ observations in the upper troposphere and lower stratosphere, J. Geophys. Res., 113, D15S02, doi:10.1029/2007JD008805, 2008.

Lucht, W., Schaaf, C. B., and Strahler, A. H.: An Algorithm for the retrieval of albedo from space using semiempirical BRDF models, IEEE T Geosci. Remote, 38, 977-998, 2000.

McPeters, R. D., Kroon, M., Labow, G. J., Brinksma, E., Balis, D., Petropavlovskikh, I., Veefkind, J. P., Bhartia, P. K., and Levelt, P. F.: Validation of the Aura Ozone Monitoring Instrument Total Column Ozone Product, J. Geophys. Res., 113, D15S14, doi:10.1029/2007JD008802, 2008.

Menzel, W. P., Wylie, D. P., and Strabala, K. I.: Seasonal and diurnal changes in cirrus clouds as seen in four years of observations with the VAS, J. Appl. Meteorol., 31, 370-385, 1992.

Mickley, L. J., Murti, P. P., Jacob, D. J., Logan, J. A., Koch, D. M., and Rind, D. H.: Radiative forcing from tropospheric ozone calculated with a unified chemistry-climate model, J. Geophys. Res., 104, 30153-30172, 1999.

Mickley, L. J., Jacob, D. J., and Rind, D. H.: Uncertainty in preindustrial abundance of tropospheric ozone: Implications for radiative forcing calculations, J. Geophys. Res., 106, 3389-3399, 2001. 
Mickley, L. J., Jacob, D. J., Field, B. D., and Rind, D. H.: Climate response to the increase in tropospheric ozone since preindustrial times: A comparison between ozone and equivalent $\mathrm{CO}_{2}$ forcings, J. Geophys. Res., 109, D05106, doi:10.1029/2003JD003653, 2004.

Minnis, P., Liou, K.-N., and Takano, Y.: Inference of cirrus cloud properties using satellite-observed visible and infrared radiances. Part I: Parameterization of radiance field, J. Atmos. Sci., 50, 1279-1304, 1993.

Nolin, A., Armstrong, R. L., and Maslanik, J.: Near Real-Time SSM/I EASE-Grid Daily Global Ice Concentration and Snow Extent, January to March 2004 (updated daily). Boulder, CO, USA: National Snow and Ice Data Center, Digital media, 1998.

Oreopoulos, L., Cahalan, R., and Platnick, S.: The plane-parallel albedo bias of liquid clouds from MODIS observations, J. Climate, 20, 5114-5125, 2007.

Pavelin, E. G., Johnson, C. E., Rughooputh, S., and Toumi, R.: Evaluation of pre-industrial surface ozone measurements made using Schonbein's method, Atmos. Env., 33, 919-929, 1999.

Petropavlovskikh, I., Froidevaux, L., Shetter, R., Hall, S., Ullmann, K., Bhartia, P. K., Kroon, M., and Levelt, P. F.: In-flight validation of Aura MLS ozone with CAFS partial ozone columns, J. Geophys. Res., 113, D16S41, doi:10.1029/2007JD008690, 2008.

Platnick, S., King, M. D., Ackerman, S. A., Menzel, W. P., Baum, B. A., Riédi, J. C., and Frey, R. A.: The MODIS cloud products: algorithms and examples from Terra, IEEE T. Geosci. Remote, 41, 459-473, 2003.

Portmann, R. W., Solomon, S., Fishman, J., Olson, J. R., Kiehl, J. T., and Briegleb, B.: Radiative forcing of the Earth's climate system due to tropical tropospheric ozone production, J. Geophys. Res., 102, 9409-9417, 1997.

Rienecker, M. M., Suarez, M. J., Todling, R., et al.: The GEOS5 data assimilation system - Documentation of versions 5.0.1, 5.1.0, and 5.2.0. NASA Tech. Memo. 2007-104606, vol. 27, edited by: Suarez, M. J., 2007.

Roelofs, G.-J., Lelieveld, J., and van Dorland, R.: A threedimensional chemistry/general circulation model simulation of anthropogenically derived ozone in the troposphere and its radiative climate forcing, J. Geophys. Res., 102, 23 389-23 401, 1997.

Roelofs, G.-J.: Radiative forcing by tropospheric ozone: impact of cloud representation, Geophys. Res. Lett., 26, 467-470, 1999.

Rossow, W. B. and Schiffer, R. A.: Advances in understanding clouds from ISCCP, B. Am. Meteorol. Soc., 80, 2261-2287, 1999.

Rozanov, V. V., Kokhanovsky, A. A., and Burrows, J. P.: The determination of cloud altitudes using GOME reflectance spectra: Multilayered cloud systems, IEEE T. Geosci. Remote, 42, 10091017, 2004.

Schoeberl, M. R., Ziemke, J. R., Bojkov, B., et al.: A trajectory-based estimate of the tropospheric ozone column using the residual method, J. Geophys. Res., 112, D24S49, doi:10.1029/2007JD008773, 2007.

Shine, K., Briegleb, B. P., Grossman, A. S., Hauglustaine, D., Mao, H., Ramaswamy, V., Schwarzkopf, M. D., Van Dorland, R., and Wang, W.-C.: Radiative forcing due to changes in ozone: a comparison of different codes, in: Atmospheric Ozone as a Climate Gas, edited by: Wang, W.-C. and Isaksen, I. S. A., NASA
ASI Series I: Global Environmental Change, Vol. 32, SpringerVerlag, Berlin, 373-396, 1994.

Sneep, M., De Haan, J., Stammes, P., Wang, P., Vanbauce, C., Joiner, J., Vasilkov, A. P., and Levelt, P. F.: Three way comparison between OMI/Aura and POLDER/PARASOL cloud pressure products, J. Geophys. Res., 113, D15S23, doi:10.1029/2007JD008694, 2008.

Solomon, S., Thompson, D. W. J., Portmann, R. W., Oltmans, S. J., and Thompson, A. M.: On the distribution of and variability of ozone in the tropical upper troposphere: Implications for tropical deep convection and chemical-dynamical coupling, Geophys. Res. Lett., 32, L23813, doi:10.1029/2005GL024323, 2005.

Stephens, G. L., Vane, D. G., Taneli, S., et al.: CloudSat Mission: Performance and early science after the first year of operation, J. Geophys. Res., 113, D00A18, doi:10.1029/2008JD009982, 2008.

Tsay, S. C., Stamnes, K., and Jayaweera, K.: Radiative energy balance in the cloudy and hazy Arctic, J. Atmos. Sci., 46, 1002 1018, 1989.

Vasilkov, A. P., Joiner, J., Spurr, R., Bhartia, P. K., Levelt, P. F., and Stephens, G.: Evaluation of the OMI cloud pressures derived from rotational Raman scattering by comparisons with other satellite data and radiative transfer simulations, J. Geophys Res., 113, D15S19, doi:10.1029/2007JD008689, 2008.

Vasilkov, A. P., Joiner, J., Yang, K., and Bhartia, P. K.: Improving total column ozone retrievals by using cloud pressures derived from Raman scattering in the UV, Geophys. Res. Lett., 31, L20109, doi:10.1029/2004GL020603, 2004.

Volz, A. and Kley, D.: Evaluation of the Montsouris series of ozone measurements made in the nineteenth century, Nature, 332, 240 242,1988

World Meteorological Organization: Atmospheric ozone, global ozone research and monitoring project, vol. I, Report No. 16, 392 pp., 1986.

Weaver, C. J., Joiner, J., and Ginoux, P.: Mineral aerosol contamination of TOVS temperature and moisture retrievals, J. Geophys. Res., 108, 4246, doi:10.1029/2002JD002571, 2003.

Wilber, A. C., Kratz, D. P., and Gupta, S. K.: Surface emissivity maps for use in satellite retrievals of longwave radiation. NASA Tech. Pub. 1999-209362, 30 pp., http://www.sti.nasa.gov, Hanover, MD, USA, 1999.

Wong, S., Wang, W.-C., Isaksen, I. S. A., Berntsen, T. K., and Sundet, J. K.: A global climate-chemistry model study of presentday tropospheric chemistry and radiative forcing from changes in tropospheric $\mathrm{O} 3$ since the preindustrial period, J. Geophys. Res., 109, D11309, doi:10.1029/2003JD003998, 2004.

Ziemke, J. R., Chandra, S., Duncan, B. N., Froidevaux, L., Bhartia, P. K., Levelt, P. F., and Waters, J. W.: Tropospheric ozone determined from Aura OMI and MLS: Evaluation of measurements and comparison with the Global Modeling Initiative's Chemical Transport Model, J. Geophys. Res., 111, D19303, doi:10.1029/2006JD007089, 2006.

Ziemke, J. R., Joiner, J., Chandra, S., Bhartia, P. K., Vasilkov, A., Haffner, D. P., Yang, K., Schoeberl, M. R., Froidevaux, L., and Levelt, P. F.: Ozone mixing ratios inside tropical deep convective clouds from OMI satellite measurements, Atmos. Chem. Phys., 9, 1-11, 2009, http://www.atmos-chem-phys.net/9/1/2009/. 